\title{
Cryptocurrencies as a financial asset: a systematic analysis
}

Article

Accepted Version

Creative Commons: Attribution-Noncommercial-No Derivative Works 4.0

Corbet, S., Lucey, B., Urquhart, A. and Yarovaya, L. (2019) Cryptocurrencies as a financial asset: a systematic analysis. International Review of Financial Analysis, 62. pp. 182-199. ISSN 1057-5219 doi: https://doi.org/10.1016/j.irfa.2018.09.003 Available at https://centaur.reading.ac.uk/79186/

It is advisable to refer to the publisher's version if you intend to cite from the work. See Guidance on citing.

To link to this article DOI: http://dx.doi.org/10.1016/j.irfa.2018.09.003

Publisher: Elsevier

All outputs in CentAUR are protected by Intellectual Property Rights law, including copyright law. Copyright and IPR is retained by the creators or other copyright holders. Terms and conditions for use of this material are defined in the End User Agreement.

\section{www.reading.ac.uk/centaur}

\section{CentAUR}

Central Archive at the University of Reading

Reading's research outputs online 


\section{Accepted Manuscript}

Cryptocurrencies as a Financial Asset: A systematic analysis

Shaen Corbet, Brian Lucey, Andrew Urquhart, Larisa Yarovaya

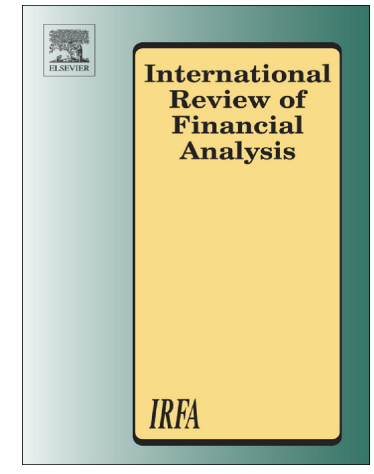

PII:

S1057-5219(18)30527-1

DOI: doi:10.1016/j.irfa.2018.09.003

Reference: FINANA 1254

To appear in: International Review of Financial Analysis

Received date: 25 June 2018

Revised date: 22 August 2018

Accepted date: 5 September 2018

Please cite this article as: Shaen Corbet, Brian Lucey, Andrew Urquhart, Larisa Yarovaya, Cryptocurrencies as a Financial Asset: A systematic analysis. Finana (2018), doi:10.1016/ j.irfa.2018.09.003

This is a PDF file of an unedited manuscript that has been accepted for publication. As a service to our customers we are providing this early version of the manuscript. The manuscript will undergo copyediting, typesetting, and review of the resulting proof before it is published in its final form. Please note that during the production process errors may be discovered which could affect the content, and all legal disclaimers that apply to the journal pertain. 


\title{
Cryptocurrencies as a Financial Asset: A systematic analysis
}

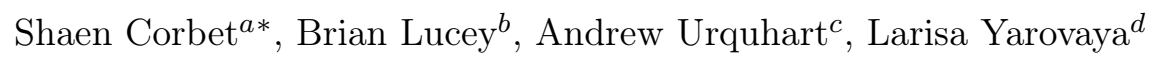 \\ ${ }^{a}$ DCU Business School, Dublin City University, Dublin 9 \\ ${ }^{b}$ Trinity Business School, Trinity College Dublin, Dublin 2 \\ ${ }^{c}$ Southampton Business School, University of Southampton \\ ${ }^{d}$ Anglia Ruskin University - Lord Ashcroft International Business School \\ *Corresponding Author: shaen.corbet@dcu.ie
}

\begin{abstract}
This paper provides a systematic review of the empirical literature based on the major topics that have been associated with the market for cryptocurrencies since their development as a financial asset in 2009. Despite astonishing price appreciation in recent years, cryptocurrencies have been subjected to accusations of pricing bubbles central to the trilemma that exists between regulatory oversight, the potential for illicit use through its anonymity within a young under-developed exchange system, and infrastructural breaches influenced by the growth of cybercriminality. Each influence the perception of the role of cryptocurrencies as a credible investment asset class and legitimate of value.
\end{abstract}

JEL Codes: F31, G18

Keywords: Cryptocurrencies; Pricing bubbles; Regulation; Cybercriminality; Systematic literature review. 


\section{Contents}

1 Introduction $\quad 3$

2 The evolution of cryptocurrencies and the Asset Class Trilemma 4

2.1 The cryptocurrency asset class trilemma . . . . . . . . . . . . 6

2.2 Do cryptocurrencies possess inherent pricing bubbles? . . . . . . . . . 8

2.3 Regulatory disorientation . . . . . . . . . . . . . . . . . 10

2.4 The growth of cryptocurrency cybercriminality . . . . . . . . . . . 13

3 Cryptocurrency market development 15

3.1 Diversification benefits . . . . . . . . . . . . . . . . . 15

3.2 Market efficiency . . . . . . . . . . . . . . . . . . . . . 18

3.2.1 Product efficiency . . . . . . . . . . . . . . . . . . . . . . 18

3.2 .2 Price efficiency . . . . . . . . . . . . . . . . . . . 19

4 Unique issues in cryptocurrency markets 20

4.1 Sustainability . . . . . . . . . . . . . . . . . . . . 20

4.2 Market correlations . . . . . . . . . . . . . . . . . . . . 21

4.3 The curious Kodak case . . . . . . . . . . . . . . . . . . 23

5 Concluding comments $\quad 25$ 


\section{Introduction}

Cryptocurrencies have attracted significant attention from investors, regulators and the media since Bitcoin was first proposed by Nakamoto [2008]. Cryptocurrencies are peer-to-peer electronic cash systems which allow online payments to be sent directly from one party to another without going through a financial institution. Therefore, unlike the vast majority of other financial assets available, they have no association with any higher authority, have no physical representation and are infinitely divisible. Also unlike traditional financial assets, the value of cryptocurrencies are not based on any tangible asset, a countries economy or a firm, but instead are based on the security of an algorithm which is able to trace all transaction. The growth of the use of cryptocurrencies can be linked to their low transaction costs, peer-to-peer system, and governmental free design. This has led to a surge in trading volume, volatility and price of cryptocurrencies, with cryptocurrencies regularly in the mainstream news.

Bitcoin is the first decentralised digital currency and remains the cryptocurrency market's leader. For the period from October 2016 to October 2017 the market capitalisation of the Bitcoin increased from $\$ 10.1$ to $\$ 79.7$ billion, while the price jumped from $\$ 616$ to $\$ 4800$ (US dollars). This significant growth presented an opportunity to obtain $680 \%$ of return on investments per year, which cannot be offered by any other assets. In December 2017 the price per Bitcoin reached $\$ 19,500$. As the blockchain space matures, Bitcoin will experience the increased competition in the nearest future (Corbet et al. [2018b]). Today, there are more than one thousand cryptocurrencies, including new products such as Ethereum, Ripple, Litecoin and Dash, who have contributed to a total market capitalisation of almost $\$ 190$ billion.

Due to the popularity of cryptocurrencies amongst users, they have attracted substantial media attention while becoming a popular topic in recent academic research. While new empirical evidence continues to emerge at a rapid pace, there is a strong need to aggregate the existing knowledge in cryptocurrency research and identify the gaps in the existing literature. This paper provides a systematic review of the empirical literature on the major topics that have attracted the attention of scholars. Our motivation to employ a systematic analysis in this study is threefold.

First, this paper is motivated by the growing amount of academic literature analysing a variety of issues associated with the rapid growth of cryptocurrency markets. Many scholars simultaneously attempt to address common research questions taken from a broad tradition of financial research, such as those based around market efficiency, asset pricing bubbles, contagion and decoupling hypotheses, volatility clustering, and the impact of news announcements and media attention (Corbet et al. [2017]), to name but a few. Many studies are conducted in parallel utilising similar datasets and employing similar methodologies consequently providing identical evidence. Besides, due to the urgency of these research problems, many papers are published in the form of short research notes, which makes it even more important for financial scholars to ensure that their research findings are 
distinctive. Therefore it is crucial to review the existing papers in this research field and to identify a current threshold of the academic quality of the studies that consider the challenges and opportunities surrounding cryptocurrencies.

Second, our study is motivated by a relative dearth of systematic literature reviews in finance. While systematic reviews become very popular in medical science, psychology, neuroscience, as well as in economics, international business and management, in finance the preference was given to more narrative literature surveys (for example, O'Connor et al. [2015]; Vigne et al. [2017]). Systematic analysis approaches can provide a more comprehensive understanding of the knowledge in the field, and the findings can change future directions of the research in this discipline by uncovering gaps in the literature. For new research areas such as those based around cryptocurrencies, a systematic analysis can be the most powerful tool to inform academics, professionals and policy-makers about the current state of knowledge, consensuses and ambiguities in the emerging discipline.

Thirdly, this review is motivated by the problem of paradigmatic unity in finance research highlighted by Lagoarde-Segot [2015]. The majority of financial papers are conducted in broad traditions of positivist research, however, often the research questions that are important for practitioners and policy-makers rely beyond this philosophical paradigm. Cryptocurrency finance research immediately adopted the same pattern. However, in cryptocurrencies, apart from standard financial problems mentioned above, there are several unique and specific issues that cannot be addressed directly using quantitative research design and data mining. For example, regulatory disorientation, cybercriminality, environmental sustainability, to name but a few. In this paper, we provide recommendations of how cryptocurrency research can be diversified in order to provide more meaningful contributions to knowledge. It is important to generate the research findings that can be useful for policy-makers, businesses, society, and can be disseminated and replicated by the scholars outside of the financial community.

The remainder of our paper is organized as follows. Section 2 investigates the evolution of cryptocurrencies and the asset class Trilemma, focusing on the potential presence of pricing bubbles, the potential for regulatory disorientation and the growth of cryptocurrency cybercriminality. Section 3 discusses the development of cryptocurrency markets with an emphasis on the diversification benefits and market efficiency. Section 4 investigates unique issues related to cryptocurrencies, discussing sustainability and market correlations while Section 5 concludes the paper.

\section{The evolution of cryptocurrencies and the Asset Class Trilemma}

The evolution of cryptocurrencies has merited the attention of academics, policy-makers and regulators alike since the evolution of Bitcoin almost a decade ago. Cryptocurrency advocates believe that there is evidence to support the asset's continued evolution as a cashless medium of exchange that can potentially change the world of finance as we know it. Opponents to the evolution of cryptocurrencies identify the role of cybercriminality and 
the unknown destabilising effects on world economies as some of the potential pitfalls of their evolution. We set out to identify these key areas of cryptocurrency research. Ninety separate research papers are included in this cryptocurrency analysis. Only two included papers were available before 2013, with only seven more being published in 2014. In 2015, eleven papers were published on the topic of cryptocurrencies, with thirteen in 2016 and thirty in 2017. At the time of writing, in 2018 there were twenty-seven papers available with significant citation available. These statistics present evidence of the strong evolution of cryptocurrency research in recent years. Table 1 identifies the key characteristics of the included explanatory and literature review based research that we have incorporated. Thirty-two papers are included, spanning the period between 2011 and 2018. We have divided the research arguments into five distinct areas: 1) Bubble dynamics; 2) Regulation; 3) Cybercriminality; 4) Diversification; and 5) Efficiency. Each of these areas is distinctly investigated in this paper.

\section{Insert Tables $1 \& 2$ about here}

Table 2 identifies the key characteristics of the fifty-two quantitative investigations of cryptocurrency markets. The research papers are sub-categorised in the same manner with data reported to include the dependent variable of the investigated methodology and indeed the type of methodology used, the rationale behind its use, the frequency and source the data used, the selected control variables and the number of observations. Figure 1 presents evidence of the duration of data coverage for the incorporated quantitative cryptocurrency research. As cryptocurrency research continues to develop, we observe that there are relatively few papers that have utilised cryptocurrency data for the entire period incorporating 2009. Much of the data possesses a starting point in 2010. While thirteen papers are directly identified as theoretical, the most common type of methodology used is that of ordinary least squares regression modelling, which has been selected by ten methodologies. Volatility methodologies such as $\mathrm{ARCH}$ and $\mathrm{GARCH}$ account for nine methodologies, with the next most common groupings incorporating a network analysis or Hurst exponent analysis. Figure 2 presents an analysis of the frequency of cryptocurrency selection as the central topic of investigation in the papers that we have analysed. Bitcoin represents the central cryptocurrency in $74.3 \%$ of the papers included. There is evidence of clear underanalysis of a number of important cryptocurrencies. Table 3 presents the core research topics of the included papers with the underlying structure of cryptocurrencies the most frequent research topic. Price dynamics is the next most popular research area with related diversification benefits, market regulation and the effects of cybercriminality presenting the following areas of frequent research. Table 4 presents evidence of the data sources used by the selected research included in our paper. Bitcoincharts.com and Coindesk.com are denoted as the two most common data sources cited in papers related to cryptocurrencies. 


\section{Insert Figure 1 and 2 and Tables $3 \& 4$ about here}

\subsection{The cryptocurrency asset class trilemma}

The evolution of the price of Bitcoin, as presented in Figure 3, generated substantial worldwide attention towards cryptocurrencies. The asset's proponents continued to point to the potential economic benefits that could be achieved, with the price of Bitcoin often increasing and decreasing by over $10 \%$. Widespread warnings were made by market commentators ${ }^{1}$, academics, regulators and policy-makers alike, concerned with the potential for an inherent bubble within cryptocurrencies. Wide-ranging arguments have been developed, however, while considering the arguments proposed by proponents and opponents alike, the sharp increase in the price of Bitcoin has been described to contain bubble-like properties (Corbet et al. [2017]) with further fears stoked by the speed to which it has occurred. We consider the relevant literature in due course but identify the potential for inherent pricing bubbles as one of the key economic risks central to the existence of cryptocurrencies at large.

\section{Insert Figures $2 \& 3$ about here}

Within the substantial price inflation of these new digital assets, contains inherent episodes of extreme volatility. This price volatility is often witnessed in the time periods surrounding two distinct undesirable features that have been predominantly associated with cryptocurrencies: 1) regulatory disorientation; and 2) cybercriminality. These two features complete the asset class trilemma that is presented in Figure 4. This trilemma develops on the three key interrelated issues that cryptocurrencies must be overcome and are each considered in Sections 2.2, 2.3 and 2.4 respectively. While there have been substantial declines in the price of Bitcoin associated with rumours of regulatory imposition, even the widespread banning of cryptocurrencies in some jurisdictions, the easing of such regulatory pressures should theoretically generate substantial price appreciation. Further, the growth of significant episodes of cybercrime continues to undermine confidence and stability in the cryptocurrency market with significant consequences (Gandal et al. [2018]; Lucey et al. [2018]). However, the presence of inherent pricing bubbles (as found by Cheah and Fry [2015]; Corbet et al. [2018a]) generate substantial rewards for those who wish to profit from such illicit tactics as cryptocurrency market hacking and theft. Growth in cybercrime also generates an immediate need for improved international regulatory alignment (Viglione [2015]), but it is also associated with the widespread banning of such financial instruments

\footnotetext{
${ }^{1}$ In an interview with Business Insider on 27 February 2018, the chief investment officer of the Investment Strategy Group of Goldman Sachs stated that cryptocurrencies at large are in a bubble and 'when it bursts, will impact only 1 percent of global GDP'
} 
in some jurisdictions, therefore further misalignment of the international regulatory approach. While considering the substantial number of issues that are directly associated with the structure, theoretical underpinnings of cryptocurrencies and broad market dynamics, research to date has mostly focused on the elements of the stated trilemma as a priority.

\section{Insert Figure 4 about here}

Regulation is one of the key factors affecting the price of cryptocurrencies, with a singular, sharp reduction in the price of Bitcoin by almost $50 \%$ in early 2018 being widely attributed to government actions in South Korea and China ${ }^{2}$. Within their own structure, cryptocurrencies are not domiciled in any single country's borders, which inherently is one of the key problems when attempting to define regulatory alignment. For example, in the United States the CFTC ${ }^{3}$ treats Bitcoin as a commodity while the IRS ${ }^{4}$ treats the same product as property. There is further evidence of broad disparity of regulation when investigating Initial Coin Offerings (ICOs) and the underlying tokens being traded on exchanges, with some tokens, escaping SEC disclosure regulations as they do not explicitly represent equity or a share in a company. Should regulation be introduced in one jurisdiction, cryptocurrency's inherent international features enable an ICO to simply take place in a state where regulatory alignment takes place. In March 2018, the SEC issued dozens of subpoenas information requests to companies and advisor's centred on ICOs and the structure of the sales.

Another major regulatory issue is the speed of cryptocurrency evolution. As cryptocurrencies develop, broad regulation is not developing in tandem, however, countries such as

\footnotetext{
${ }^{2}$ In January 2018, it was widely reported that finance regulators in South Korea were looking to cooperate with authorities in China and Japan on new rules for cryptocurrency trading. A Jan. 8 report by Yonhap News states that representatives from the Korean Financial Services Commission (FSC), as well as those from the relevant agencies in Japan and China, met in December 2017 to discuss the oversight of cryptocurrency investment. After this subsequent news release, cryptocurrency prices fell with Bitcoin experiencing losses in excess of $50 \%$ in one month.

${ }^{3}$ The U.S. Commodity Futures Trading Commission (CFTC) is an independent agency of the US government created in 1974, that regulates futures and option markets. The stated mission of the CFTC is to foster open, transparent, competitive, and financially sound markets, to avoid systemic risk, and to protect the market users and their funds, consumers, and the public from fraud, manipulation, and abusive practices related to derivatives and other products that are subject to the Commodity Exchange Act. After the Financial crisis of 2007-08 and since 2010 with the Dodd-Frank Wall Street Reform and Consumer Protection Act, CFTC has been transitioning to bring more transparency and stricter regulation to the multi-trillion dollar swaps market.

${ }^{4}$ The Internal Revenue Service (IRS) is the revenue service of the United States federal government. The government agency is a bureau of the Department of the Treasury, and is under the immediate direction of the Commissioner of Internal Revenue, who is appointed to a five-year term by the President of the United States.
} 
South Africa and their Reserve Bank have taken a 'sandbox' approach to regulation which attempts to mitigate inherent pitfalls without stifling their development. A further major issue surrounds that of anonymity, which must be addressed to undermine issues such as money-laundering and general misappropriation of funds, particularly when considering the ease of cross-border transfer of cryptocurrencies. This regulation vacuum has deterred some major banking corporations from conducting business with cryptocurrency traders, further undermining the reputation of the new financial products.

In January 2018, confidence in broad cryptocurrency exchanges was dealt a significant blow due to hacking of $\$ 530$ million from Coincheck, eclipsing the prior record of $\$ 400$ million reported to have been stolen from the Mt.Gox hacking event in 2014. The hackers had stolen customer deposits of NEM, which then fell approximately $20 \%$ as news broke to the public about the hack. This followed the closure of South Korean Bitcoin exchange Youbit who recently filed for bankruptcy after being the target of two significant hacking events in quick succession. In December 2017, hackers stole approximately $\$ 70$ million worth of Bitcoin from NiceHash which is a digital currency trading platform based in Slovenia. Such events have created further focus and desire for the regulation of the entire industry, but this has simultaneously been associated with widespread price volatility. There has been further cybercriminality detected with regards to the hacking of internet-connected devices in an attempt to utilise computing power to mine digital coins such as Monero ${ }^{5}$.

\subsection{Do cryptocurrencies possess inherent pricing bubbles?}

One of the most immediate issues for cryptocurrencies at large is the potential existence of an inherent pricing bubble. Corbet et al. [2017] built on the work of Phillips et al. [2011] and Phillips et al. [2015] to examine the existence and dates of potential pricing bubbles in the markets for Bitcoin and Ethereum. Having derived ratios based on fundamental drivers using data from 2009 to 2017, the author's present evidence that Bitcoin was almost certainly in a bubble phase in late 2017. This echoed the findings of Cheung et al. [2015] who focused on the collapse of Bitcoin's largest exchange Mt. Gox ${ }^{6}$ to identify numerous

\footnotetext{
${ }^{5}$ Monero (XMR) is an open-source cryptocurrency created in April 2014 that focuses on privacy and decentralization that runs on Windows, macOS, Linux, Android, and FreeBSD. Monero uses a public ledger to record transactions while new units are created through a process called mining. Monero aims to improve on existing cryptocurrency design by obscuring sender, recipient and amount of every transaction made as well as making the mining process more egalitarian. The focus on privacy has attracted illicit use by people interested in evading law enforcement. The egalitarian mining process made it viable to distribute the mining effort opening new funding avenues for both legitimate online publishers and malicious hackers who covertly embed mining code into websites and apps.

${ }^{6}$ Mt.Gox was a Bitcoin exchange based Tokyo, Japan which launched in July 2010 and by 2013 it was handling over $70 \%$ of all Bitcoin transactions worldwide, as the largest Bitcoin intermediary and the world's leading Bitcoin exchange. However, in February 2014, Mt.Gox suspended trading, closed its website and exchange service, and filed for bankruptcy protection from creditors. In April 2014, the company began liquidation proceedings. Mt.Gox then announced that approximately 850,000 Bitcoins belonging to customers and the company were missing and likely stolen, an amount valued at more than $\$ 450$ million at
} 
short-lived bubbles over the period 2010 through 2014. They specifically identify three very large bubbles in the latter part of their sample lasting from 66-106 days. The final bubble that they identify is described as being that which 'broke the camels back' and caused the demise of Mt.Gox. Cheah and Fry [2015] found that Bitcoin exhibits speculative bubbles with further empirical evidence provided that the fundamental price of Bitcoin is zero. The author's further note that Bitcoin seems to behave more like an asset than a currency, with the main attraction appearing to be sourced in it's role as a speculative asset instead of functioning as money, particularly as $70 \%$ of existing Bitcoins are held in dormant accounts (Weber [2014]). Fry and Cheah [2016] test the existence of bubbles using data from 2011 through 2015 using a multivariate methodology. Drawing from statistical physics and mathematics, the authors find evidence for a negative bubble from 2014 onwards in the two largest cryptocurrencies, Bitcoin and Ripple. Evidence also suggests that there is a spillover from Ripple to Bitcoin that exacerbates price decreases in the latter, with Ripple being the most over-priced of the two. Baek and Elbeck [2015] use the S\&P500 to examine relative volatility with Bitcoin using de-trended ratios to find that Bitcoin is internally driven by buyers and sellers, therefore concluding that the Bitcoin market is highly speculative.

Blau [2018] investigated the volatility of Bitcoin across time while testing as to whether the unusual level of the product's volatility is attributed to speculative trading. Using data based on the period July 2010 through June 2014, it is found that this speculative trading did not have any relationship with the 2013 price increases nor the dramatic increases in volatility. Gkillas and Katsiampa [2018] study the tail behaviour of the returns of five major cryptocurrencies using Value-at-Risk and Expected Shortfall to find that Bitcoin Cash $^{7}$ is the riskiest cyrptocurrency, while Bitcoin and Litecoin are the least risky. Peng et al. [2018] provide an evaluation of the predictive performances of the volatility of crytpocurrencies using daily and hourly-frequency data to find that the Support Vector Regression (SVR)-GARCH methodology managed to outperform that of GARCH, EGARCH and GJR-GARCH models with Normal, Student's $t$ and Skewed Student's $t$ distributions. The predictive ability of their models was evaluated using the Diebold-Mariano test (Diebold and Mariano [2002]) and Hansen's Model Confidence Set Hansen et al. [2011]. Phillip et al. [2018] used a cross-section analysis of 224 different cryptocurrencies to identify several unique properties including leverage effects and Student $t$ error distributions. Jang and Lee [2017] use Bayesian Neural Networks (BNN) while incorporating the the underlying fundamentals of Bitcoin to present evidence of a well-performed predictor of Bitcoin price time series while explaining the high volatility of Bitcoin in recent times. While Polasik et al. [2015] look at country, customer and company-specific characteristics interactions with the proportion of sales attributed to Bitcoin, the underlying fundamentals are of considerable

\footnotetext{
the time.

${ }^{7}$ Bitcoin Cash $(\mathrm{BCH})$ is a hard fork of the cryptocurrency Bitcoin. The Bitcoin scalability debate led to the hard fork on 1 August 2017, which resulted in the creation of a new blockchain.
} 
interest when attempting to monitor potential bubbles in the market for cryptocurrencies, particularly issues such as power consumption and mining expense. Vranken [2017] estimated that the order of magnitude for energy consumption is $100 \mathrm{MW}$, therefore, as Bitcoin becomes more popular the effort for Bitcoin mining becomes substantially more difficult, leading to the sole survival of those miners that possess the most competitive mining equipment with access to the cheapest electricity costs. This shifting economic structure could potential generate monopolistic pricing influences.

Fry [2018] introduced a rational bubble model for Bitcoin and other cryptocurrencies that combines both heavy tails and the probability of a complete collapse in asset prices which makes this model a theoretical refinement of the model by Cheah and Fry [2015]. In the absence of the central cryptocurrency market regulation the possibility that whole market can collapse is higher for cryptocurrencies than for other assets. The paper provides evidence of a bubble in Bitcoin and Ethereum, while no evidence of a bubble in Ripple. Bouri et al. [2018] analysed price explosivity of 7 largest cryptocurrencies by market capitalisation using daily data from August 7, 2015 to December 31, 2017. The results show that all cryptocurrencies in the sample (Bitcoin, Ripple, Ethereum, Litecoin, Nem, Dash, and Stellar) experienced explosive behaviours in multiple periods. Furthermore, the study provides evidence of a multidirectional co-explosivity behaviour, i.e. explosivity in one cryptocurrency can lead to explosivity in other cryptocurrencies, while this effect does not necessarily depend on the size of each cryptocurrency.

Investor attention is also observed as a key determinant of potential market mis-pricing as discussed in Shiller [2000], Baker and Wurgler [2007] and Andrei and Hasler [2014]. Using a VECM methodology, Mai et al. [2015] found that social media effects are mostly driven by those who use social media less often, otherwise known as the silent majority. Further, messages on internet forums are found to have stronger impacts on Bitcoin returns relative to tweets. Through the use of a significant database spanning 2010 through 2017, Urquhart [2018] found that realised volatility and the volume of Bitcoin traded, controlled for Bitcoin fundamentals, are both significant drivers of the next day's attention for Bitcoin. Balcilar et al. [2017] show that volume cannot help to predict the volatility of Bitcoin returns at any point of the conditional distribution, but can predict returns with the exception of Bitcoin, bull and bear market regimes.

\subsection{Regulatory disorientation}

The regulation of cryptocurrencies presents both a unique and monumental challenge to policy-makers. Many countries have threatened to introduce blanket-bans against the use and trading of cryptocurrencies, but few have yet to introduce such regulation. In late-2017 and early-2018 the widespread threat of regulatory intervention by countries such as South Korea and China was widely attributed to a substantial decrease in the value of Bitcoin. In January 2018, the South Korean Financial Services Commission introduced measures to ban anonymous trading on domestic exchanges, while foreigners and minors would be completely banned from trading through cryptocurrency accounts. Chinese regulators have sought to 
increase regulation banning initial coin offerings (ICOs), the supervision of foreign currency flows and increasing transparency within cryptocurrency exchanges. Potential inter-linkage between Bitcoin and issues such as, but not limited to, the funding of terrorism, the potential for money substitution and the potential for tax-evasion and cross-border wealth transfer have led to blanket and partial bank in Thailand and China (2013); Russia, Vietnam, Bolivia, Ecuador, Kyrgyzstan and Bangladesh (2014); Taiwan (2015); Columbia (2016); and Nigeria (2017). In addition, social media platform Facebook in 2018 introduced an advertising policy that prohibits advertisement pertaining to cryptocurrency, binary options and ICOs. The policy was introduced as part of an ongoing effort to improve the integrity and security of Facebook advertisement while simultaneously making it more difficult for fraudsters to generate illegal profit from vulnerable social media users. Cryptocurrencies had provided a perfect medium from which this form of fraud could thrive.

Brito et al. [2014] state that while Bitcoin-related regulation has been largely focused on customer-based anti-money laundering regulation, the authors find that financial regulators should consider exempting or excluding certain financial transactions denominated in Bitcoin from the full scope of the regulations, similar to that of private securities offerings and forward contracts to encourage resilience and adoption and to ensure that regulatory costs do not eventually outweigh the benefits of cryptocurrencies. Hendrickson and Luther [2017] employ a monetary model with endogenous search and random consumption preferences to consider the extent to which a government can ban a cryptocurrency to show that this can be achieved without a reliance on punishments but is dependent on the size of the government. Böhme et al. [2015], while focusing on the governance of Bitcoin note that although its design originally set out to provide a service, new constituent are now being added but it is not clear if they aspire to meet prevailing requirements. While the underlying foundations of Bitcoin appear to be locked in place, there are numerous competing virtual currencies that can act as a ready replacement. Atzori [2015] advocates the role of the State as a necessary central point of coordination in society, showing that decentralisation through algorithm-based consensus is an organisational theory, but not a stand-alone political theory. The authors highlight key risks related to a dominant position of private powers in distributed econosystems. Rohr and Wright [2017] argues that the SEC and Congress should provide token sellers and the exchanges that facilitate token sales with additional certainty while providing guidance on how the Howey test $^{8}$ should be applied to digital tokens. In support of lighter regulation, Luther and Salter [2017] found that downloads for fifteen Bitcoin apps available at the time of the bailout in Cyprus increased in the aftermath of its announcement. However, the authors state that the increased number of downloads was not especially pronounced in countries identified as having a troubled

\footnotetext{
${ }^{8}$ The Howey Test is a test created by the Supreme Court for determining whether certain transactions qualify as investment contracts. If so, then under the Securities Act of 1933 and the Securities Exchange Act of 1934, those transactions are considered securities and therefore subject to certain disclosure and registration requirements.
} 
banking system.

Regulatory issues are not confined to money-laundering aspects and as to whether the costs of cryptocurrency barriers could hinder the potential benefits. Marian [2013] and Gross et al. [2017] focus on the taxation implications of cryptocurrencies with the provision of a specific warning that even though Bitcoin and broad cryptocurrencies exist in a digital form, we cannot assume that their influence will be solely digital. Their use can theoretically generate effects within the real economy. Further, their existence needs international consideration as to whether they should be treated as currency or property and whether they are subject to capital gains and losses regulations ${ }^{9}$. The tax treatment of broad cryptocurrencies is further driven by its financial status. Grinberg [2012] focused on the potential for separation of Bitcoin from it's legal 'grey area' with identification of it's potential inclusion in general anti-fraud legislation should it be considered a security in the future. Tasca et al. [2016] utilise a network analysis to map payment relationships in an attempt to analyse transaction behaviour segregated by business category. They show that the market has matured in three stages: 1) an early prototype stage; 2) a second stage interlinked with 'sin' products and enterprises; and 3) a third stage marked with a progression towards legitimate enterprise. This provides evidence of an evolution of the cryptocurrency market.

Savelyev [2017] investigate copyright in the blockchain era to point out that blockchain could offer potential transparency advantages in the area, particularly around piracy of digital content and the protection of revenue streams through cryptocurrency payments and smart contracts, however, many of the legal aspects of blockchain need to be immediately considered. Bollen [2013] note that there are significant legal issues surrounding the fact that Bitcoin does not have an issues but this should not cause regulatory issues.

With regards to the regulation of price dynamics, Gandal et al. [2018] investigate the impact of suspicious trading activity on the Mt.Gox currency exchange during it's demise in 2013. Based on a rigorous analysis with extensive robustness checks the authors demonstrate that during periods identified as 'suspicious', this trading activity is found to have likely caused the unprecedented increase in te US dollar-Bitcoin (USD-BTC) exchange rate in late 2013 when it increased from around $\$ 150$ to more than $\$ 1,000$ in two months. Viglione [2015] investigated the effects of social technologies related to the governance on cross-country differences in Bitcoin prices as controlled for financial freedom, to which a

\footnotetext{
${ }^{9}$ For example, in the United State if you spend or invest in virtual currencies, it is crucial to understand how virtual currency transactions are treated for tax purposes. The Internal Revenue Service (IRS) addressed the taxation of virtual currency transactions in Notice 2014-21. According to the Notice, virtual currency is treated as property for federal tax purposes. This means that, depending on the taxpayer's circumstances, cryptocurrencies, such as Bitcoin, can be classified as business property, investment property, or personal property. General tax principles applicable to property transactions must be applied to exchanges of cryptocurrencies. Hence, Notice 2014-21 holds that taxpayers recognize gain or loss on the exchange of cryptocurrency for other property. Accordingly, gains or losses are recognised every time that Bitcoin is used to purchase goods or services.
} 
positive correlation is found. Bitcoin is therefore observed as a new channel that can offer evasion of domestic jurisdiction. Dwyer [2015] explains how the use of peer-to-peer networks and open source software combined with the limitation of quantity produced creates an equilibrium in which a cryptocurrency has a positive value. The use of such technology is designed to prevent users from spending their balances more than once, also known as the double-spending problem ${ }^{10}$.

\subsection{The growth of cryptocurrency cybercriminality}

To complete the trilemma we focus on that of cybercriminality, which is found to take two broad forms: 1) Cybercrime stemming from the use of cryptocurrencies; and 2) Cybercrime influencing the direct structures of cryptocurrencies themselves. Despite existing for less than a decade, cryptocurrencies have experienced a broad variety of both types of cybercriminality which merit significant regulatory attention, which perhaps influence the presence of market mis-pricing and to which we briefly discuss.

The largest example of cybercriminality sourced from the use of cryptocurrency was that of Silk Road, which was an online black market used to sell drugs on the dark web ${ }^{11}$. The website was launched in February 2011, where sellers had to purchase an account in an auction, but this was later changed to a fixed fee. In October 2013, the FBI shut down the website and arrested Ross Ulbricht. On 6 November 2013, Silk Road version 2.0 (v2.0) went online, however, it was also shut down. On news of the closure of Silk Road, Bitcoin fell from approximately $\$ 145$ to $\$ 109$. This was because of the cryptocurrencies widespread use due to the provision of anonymity while completing online drug deals. The FBI had estimated that Silk Road had accounted for almost $5 \%$ of the total Bitcoin economy. Bitcoin presented evidence of resilience during its survival of the Silk Road closure.

The second form of cybercriminality is denoted as cybercriminality attacking the direct structures of cryptocurrencies. A December 2017 report released by Ernst \& Young ${ }^{12}$ stated that the total amount of funds raised by ICOs is approaching $\$ 4$ billion (US) which is found to be twice the volume of venture capital investments in blockchain projects.

\footnotetext{
${ }^{10}$ Double-spending is a potential flaw in a digital cash scheme in which the same single digital token can be spent more than once. This is possible because a digital token consists of a digital file that can be duplicated or falsified. As with counterfeit money, such double-spending leads to inflation by creating a new amount of fraudulent currency that did not previously exist. This devalues the currency relative to other monetary units, and diminishes user trust as well as the circulation and retention of the currency. Fundamental cryptographic techniques to prevent double-spending while preserving anonymity in a transaction are blind signatures and particularly in off-line systems, secret splitting.

${ }^{11}$ The dark web is the World Wide Web content that exists on darknets, overlay networks that use the Internet but require specific software, configurations or authorization to access. The darknets which constitute the dark web include small, friend-to-friend peer-to-peer networks, as well as large, popular networks like Tor, Freenet, and I2P, operated by public organizations and individuals. Users of the dark web refer to the regular web as Clearnet due to its unencrypted nature.

${ }^{12}$ Located at: http://www.ey.com/Publication/vwLUAssets/ey-research-initial-coin-offerings-icos/
} 
Disturbingly, the report estimates that almost $10 \%$ of all ICO proceeds are stolen by hackers. While this is an incredible indictment of the ICO process, it is not the only mechanism through which cryptocurrency investors have been defrauded. Hacking both exchanges and cryptocurrency wallets has become more widespread and more severe in the recent past. The most substantial cases include:

1. The DAO was established as an Ethereum-based venture capital organization that was governed by all of its participants. It was envisioned to be a robust platform that enabled the creation and implementation of DApps (Decentralized Applications) on its platform. The crowdfunding for the DAO raised more than $\$ 150$ million in Ether in May 2016. By the following month, hackers exploited a flaw in the DAO and stole $\$ 50$ million.

2. Bitfinex is a Hong Kong-based cryptocurrency exchange platform owned by iFinex Inc. It also provides wallet and trading services for cryptocurrencies. Bitfinex has suffered a few hacks during its time of operation but the biggest hack was in 2016 when almost 120,000 BTC were stolen from the platform. This amounted to about $\$ 72$ million and it is the second largest Bitcoin exchange hack.

3. Established in 2010, Bitfinex quickly grew to the pinnacle of the Bitcoin trading market. It came crashing down after the biggest cryptocurrency hack occurred on the platform in 2014. It resulted in the theft of over 700,000 BTC worth about $\$ 473$ million.

4. In January 2018, hackers broke into a cryptocurrency exchange called Coincheck Inc. and made off with nearly $\$ 500$ million in digital tokens. It's one of the biggest heists in history, with the exchange losing more than 500 million of NEM coins.

Gandal et al. [2018] presented an overview of the key issues associated with technological advances, however, cryptocurrencies due to their anonymous characteristics have been linked with numerous types of crimes including 'facilitating marketplaces for: assassins; attacks on businesses; child exploitation (including pornography); corporate espionage; counterfeit currencies; drugs; fake IDs and passports; high yield investment schemes; sexual exploitation; stolen credit cards and credit card numbers; and weapons'. Göbel et al. [2016] use a simplified Markov model that tracks the contrasting states of belief about the blockchain of a small pool of dishonest miners and the rest of the community to establish the use of block-hiding strategies, then using discrete-event simulation to study the behaviour of the network. Their results indicate that both the honest and dishonest miners were worse off than they would have been if no dishonest mining was present. Glaser et al. [2014] found strong evidence supporting the view that uninformed users approaching digital currencies were not primarily interested in an alternative transaction system, but instead, it's inherent secondary uses and role as an alternative investment vehicle, while Vandezande [2017] attempted to investigate the effects of anti-money laundering legislation on cryptocurrencies in the European Union. Pieters and Vivanco [2017] found evidence 
of regulation failure, cross-exchange price variation and strong differences across markets that do not require customer identification for establishing an account. The latter result is found to be related to cross-exchange price variation.

Houy [2014] found that an attacker is equally as likely to be successful when attacking cryptocurrencies who implement a proof-of-stake transaction validation scheme are less vulnerable to a $51 \%$ attack than those cryptocurrencies implementing a proof of work transaction validation system despite the widely held belief that the former strategy was risk-mitigating. Pinzón and Rocha [2016] investigated time advantages to attacker agents in the Bitcoin network to present two different attack models and an algorithmic experimentation comparing the models to present evidence that advantages are non-negligible for cases when the attacker has enough time to mine fraudulent blocks on the network. The authors develop methodologies to correctly model and detect double-spending attacks. Gramoli [2017] discussed the advantage of the blockchain Byzantine consensus definition over previous definitions in comparison to emerging consistent blockchains to discuss the dangers of using these blockchains without understanding precisely the guarantees that their consensus algorithms offer. Zimba et al. [2018] model multi-stage cryptocurrency ransomware attacks using WannaCry ransomware ${ }^{13}$. Wang et al. [2017] conducted a systematic study on the security threats to blockchain while reviewing potential security enhancement solutions that could be used in the development of various blockchain solutions. Trautman [2013] proposed the concept of DV-PoA (designated-verifier proof of assets) for Bitcoin exchanges using elliptic curve cryptography which they prove to be secure and efficient. Li et al. [2017] propose a framework to present greater transparency to the users of cryptocurrencies through the reduction of sensitive information such as the amount traded using the Paillier cryptosystem for encryption and decryption in an attempt to mitigate active and passive attacks.

\section{Cryptocurrency market development}

\subsection{Diversification benefits}

Brière et al. [2015] found using spanning tests that Bitcoin investments offer significant diversification benefits to show that the inclusion of even a small proportion of Bitcoins may dramatically improve the risk-return trade-off of well-diversified portfolios. The authors, however, state that the results should be taken with caution as the data may reflect early

\footnotetext{
${ }^{13}$ The WannaCry ransomware attack was a May 2017 worldwide cyberattack by the WannaCry ransomware cryptoworm, which targeted computers running the Microsoft Windows operating system by encrypting data and demanding ransom payments in the Bitcoin cryptocurrency. It propagated through EternalBlue, an exploit in older Windows systems released by The Shadow Brokers a few months prior to the attack. While Microsoft had released patches previously to close the exploit, much of WannaCry's spread was from organizations that had not applied these, or were using older Windows systems that were past their end-of-life. WannaCry also took advantage of installing backdoors onto infected systems.
} 
stage behaviour which may not last in the medium or long-run. Corbet et al. [2018a] analyse in time and frequency domains, the relationships between the three most popular cryptocurrencies and a variety of other financial assets to find evidence of the relative isolations of these assets from the financial and economic assets. Results show that cryptocurrencies may offer diversification benefits for investors with short-term investment horizons. Baur et al. [2017] analysed the statistical properties of Bitcoin to find that it is uncorrelated with traditional asset classes in periods of financial turmoil. Transaction data of Bitcoin accounts show that Bitcoins are mainly used as a speculative investment and not as an alternative currency or medium of exchange. Dyhrberg [2016a] export the financial asset capabilities of Bitcoin using GARCH methodologies, showing several similarities to gold and the dollar, indicative of hedging capabilities and advantages as a medium of exchange. Bitcoin is found to have a place on financial markets and it can be classified as something in between gold and the US dollar on a scale from pure medium of exchange advantages to pure store of value advantages. Baur et al. [2017] extended the work of Dyhrberg [2016a] to replicate the above findings and demonstrates that exact replication is not possible and that alternative statistical methodologies provide more reliable, however, very different returns. The findings show that Bitcoin exhibits distinctively different return, volatility and correlation characteristics compared to other assets including gold and the United States dollar. Dyhrberg [2016b] show that Bitcoin can be used as a hedge against stocks in the Financial Times Stock Exchange Index and against the US dollar in the short-term. Bitcoin is thereby found to possess some of the same hedging abilities as gold and can be included in the variety of tools available to market analysts to hedge market-specific risk. Bouri et al. [2017] used a dynamic conditional correlation model to examine whether Bitcoin can act as a hedge and safe have for four major world stock indices, bond, oil, gold, the general commodity index and the US dollar index using data between July 2011 and December 2015. The empirical results indicate that Bitcoin is a poor hedge and is suitable for diversification purposes only. Bouri et al. [2017] examined whether Bitcoin can hedge global uncertainty as measured by the first principal component of the VIX and fourteen developed and developing equity markets to reveal that Bitcoin does act as a hedge against uncertainty. Demir et al. [2018] analysed the prediction power of the economic policy uncertainty index (EPU) index on daily Bitcoin returns using Bayesian Graphical Structural Vector Autoregressive modelling with Ordinary Least Squares and Quantile-on-Quantile Regression estimations. Results find that the EPU has predictive power on Bitcoin returns with a primarily negative association, with Bitcoin serving as a purposeful hedging tool against uncertainty.

Ciaian et al. [2018] used an ADRL methodology to examine the interdependencies between Bitcoin and Atlcoin markets in the short and long-run for the period between 2013 and 2016 to find that both markets are interdependent. The relationship is found to be significantly stronger in the short-run than in the long-run, where macro-financial indicators determine the Altcoin price formation to a slightly greater degree than Bitcoin does. Selgin [2015] discuss diversification benefits of the use of cryptocurrencies through the role of 'synthetic commodity money' which is best described as a product that shares features 
of 'commodity' and 'fiat' base money, resembling fiat money which has no non-monetary value and commodity money in that it is absolutely scarce. The authors argue that these special characteristics of synthetic commodity money might allow for the supply of foundations for a monetary regime that does not require oversight by any monetary authority but might be able to provide for a high degree of macroeconomic stability. Turk and Klinc [2017] investigated the diversification benefits of blockchain by focusing on its potential use in the construction industry. The authors concluded that while blockchain appears to provide solutions to some industry problems, it is more likely that it will be built into generic IT infrastructure on top of which construction applications are built, potentially making the construction process less centralised. Recently, Urquhart and Zhang [2018] assess the relationship between Bitcoin and currencies at the hourly frequency find that Bitcoin can be an intraday hedge for the CHF, EUR and GBP, but acts as a diversifier for the AUD, CAD and JPY. They also find that Bitcoin is a safe haven during periods of extreme market turmoil for the CAD, CHF and GBP. Recently, Platanakis and Urquhart [2018] have examined the diversification benefits of adding Bitcoin to a stock-bond portfolio and find that the out-of-sample benefits are quite considerable with substantially higher Sharpe, Sortino and Omega ratios, which hold across all different asset allocation strategies and risk aversions. Further, Platanakis et al. [2018] examine the performance of naïve $(1 / \mathrm{N})$ and optimal (Markowitz) diversification in a portfolio of four popular cryptocurrencies and show there is very little to select between naïve diversification and optimal diversification.

Brauneis and Mestel [2018a] assessed the effects of diversified cryptocurrency investments in a traditional Markowitz mean-variance framework using a broad sample of the 500 most capitalized cryptocurrencies as of December 2017 employing daily data from January 1, 2015 to 31 December, 2017. Paper identifies that naively diversified portfolios outperform the mean-variance optimized portfolios. Similar results reported by Liu [2018] who analysed the diversification benefits of cryptocurrency markets. Findings show that naïve $1 / \mathrm{N}$ portfolio of cryptocurrencies consistently demonstrate better performance than other asset allocation models. Guesmi et al. [2018] analyses the conditional cross effects and volatility spillover between Bitcoin and other financial assets providing evidence that Bitcoin can offer diversification benefits and hedging opportunities for investors. Particularly, the results shows that hedging strategies involving gold, oil, emerging stock markets and Bitcoin reduce considerably a portfolio's variance in comparison to the variance of a portfolio composed of gold, oil and stocks from emerging stock only.

Giudici and Abu-Hashish [2018] Guidici and Abu-Hashish (2018) developed an extended Vector Autoregressive model based on network models that introduce a contemporaneous contagion component that describes contagion effects between assets prices. The model employed to Bitcoin prices from various exchanges and also other assets prices such as gold, oil, SP500, and USD-Yuan and USD-Euro exchange rates. The results show that bitcoin prices from different exchanges are highly interrelated, while bitcoin prices are unrelated with prices of other assets. The relationships between Bitcoin and other assets have been also analysed by Ji et al. [2018] who employed a data-driven methodology, so-called the 
direct acyclic graph, to daily index values for Bitcoin, stock, bonds, commodities and currencies for the period from 19 July 2010 to 31 January 2017. Authors found that Bitcoin is isolated from other assets, and none of the selected assets can significantly influence the Bitcoin market. However, the paper reports the existence of lagged relationships between Bitcoin and other assets during the beer market. This can be explained by the fact that herding behaviour in cryptocurrencies tends to occur as uncertainty increases (Bouri et al. [2018]). Time-varying herding behaviour limits portfolio diversification benefits has implications to market efficiency and justifies the importance of regulation.

\subsection{Market efficiency}

Market efficiency can be determined by a number of specific factors, however, cryptocurrencies market efficiency can be measured through a host of progressive factors including the existence of a new futures exchange, liquid cross-currency indices and the relative reduction of intra-day volatility, although daily volatility remains high. In this section, we separate market inefficiency into product efficient, as well as price efficiency.

\subsubsection{Product efficiency}

Bouoiyour and Selmi [2015] use ARDL bounds testing to reveal extremely speculative behaviour of Bitcoin, its partial usefulness in trade transactions without overlooking its dependence to the Shanghai Stock Market and the hash-rate ${ }^{14}$. The authors find no evidence of Bitcoin providing a safe haven while Roth [2015] investigated the architectural structure of Bitcoin using a functional analysis by employing the Systems Modelling Language (SysML). Luther [2016] stated that blockchain technology may be adopted if it significantly reduces the costs of processing transactions. However, Bitcoins and Altcoins are unlikely to function as more than a niche money except in the unlikely event of hyperinflation, government support or both. Harvey [2014] further support the continued growth of Bitcoin should a range of price volatility and regulatory problems be overcome. Demir et al. [2018] show that any situation with a fixed fee is equivalent to another situation with a limited block size. By making the block size a non-binding constraint and at the same time letting the fee be fixed as the outcome of a decentralised competitive market cannot guarantee the existence of Bitcoin in the long-run. Prybila et al. [2017] investigate runtime verification for a business process using the Bitcoin blockchain which is realised using a fully functional software prototype. The authors show that their blockchain-based approach enables a seamless execution monitoring and verification of choreographies while simultaneously preserving anonymity and independence of the process participants. Huang et al. [2018] investigate fog computing which can be viewed as an extension of cloud computing that enables transactions and resources at the edge of the network. The authors propose a fair

\footnotetext{
${ }^{14} \mathrm{~A}$ hash is the output of a hash function and, as it relates to Bitcoin, the hash-rate is the speed at which a compute is completing an operation in the Bitcoin code. A higher hash rate is better when mining as it increases your opportunity of finding the next block and receiving the reward.
} 
payment scheme for outsourcing computations based on Bitcoin. Due to the advantages of Bitcoin syntax, the users can transact directly without needing a bank. The author's proposed construction can guarantee that no matter how a malicious outsourcer behaves, the honest workers will be paid if he/she completed the computing tasks. Delgado-Segura et al. [2017] present a fair protocol for data trading where the commercial deal, in terms of delivering the data and performing the payment is atomic since the seller cannot redeem the payment unless the buyer obtains the data and the buyer cannot obtain the data without performing the payment. Maesa et al. [2017] investigate the behaviour of blockchain users through an analysis of the topological properties showing that the structural properties of the network are due to peculiar unusual patterns in the network graph which are found to be due to artificial users' behaviours and not strictly related to normal economic interactions. Lahmiri and Bekiros [2018] investigate, assess and detect chaos, randomness, and multiscale temporal correlation structure in prices and returns of this specific virtual and speculative market throughout two distinct time periods; namely under a low-level regime period during which prices slowly increased, and during a high and turbulent regime time period whereby they exponentially increased. The authors found evidence that the level of uncertainty in returns has significantly increased during the high-price time period compared to the low-price period. Both prices and returns exhibit long-range correlations and multifractality. The fat-tailed probability distributions are the main source of multi-fractality in the time series of prices and returns. Furthermore, short (long) fluctuations in returns are dominant during low (high) price-regime time period, respectively.

The existence of structural breaks in Bitcoin volatilities has been also reported by Ardia et al. [2018]. Authors found that a two-regime MSGARCH model demonstrated the best insample forecasting performance with an inverted leverage effect in low- and high- volatility regimes, while for one-day ahead forecast Ardia et al. [2018] report that Value-at-Risk Markov-switching specifications out-perform standard single-regime GARCH models. The impact of structural breaks (SB) on the dual long memory levels of Bitcoin and Ethereum price returns analysed by Mensi et al. [2018]. Results show the dual long memory property of Bitcoin and Ethereum which contradict the efficient market hypothesis. Mensi et al. [2018] also found that after accounting for structural breaks the long memory in the mean and variance significantly decreases. Finally, a study by Thies and Molnar [2018] also indicate the existence of frequent structural breaks in Bitcoin returns providing evidence from Bayesian change point model.

\subsubsection{Price efficiency}

Price efficient refers to the Efficient Market Hypothesis, which has been examined extensively in the literature. Urquhart [2016] was the first to examine the market efficiency of Bitcoin and found through a battery of tests that Bitcoin was inefficient, although it was becoming less inefficient over time. The result of the inefficiency of Bitcoin has been supported in follow-up studies that have used a range of different testing procedures and different data sets, where examples are Bariviera et al. [2017], Jiang et al. [2017], Nadarajah 
and Chu [2017], Alvarez-Ramirez et al. [2018], Brauneis and Mestel [2018b], Caporale et al. [2018], Cheah et al. [2018], Khuntia and Pattanayak [2018], Lahmiri and Bekiros [2018], Sensoy [2018], Tiwari et al. [2018] and Vidal-Tomás and Ibañez [2018].

For example, Charfeddine and Maouchi [2018] found that the long-range dependence behaviour has been exhibited by the returns and volatilities of Bitcoin, Litecoin, and Ripple, while for Ethereum the long-range behaviour has been observed only in volatility series. The findings support the position of Urquhart [2016] on the relative inefficiency of cryptocurrency markets, which again can be explained by their immaturity. For Bitcoin, Takaishi and Adachi [2018] provided evidence of the Taylor effect which indicates that the real return time series is expected to have a richer time structure in time series than the random walk process, supporting the inefficiency of Bitcoin.

Therefore the literature suggests that Bitcoin returns do not conform to the Efficient Market Hypothesis and that Bitcoin returns are not independent but predictable. This is further documented by Urquhart [2017] who found significant evidence of clustering at round numbers, with over $10 \%$ of prices ending with 00 decimals compared to other variations but there is no significant pattern of returns after the round number, while further supporting the hypothesis of Harris (1991) by showing that price and volume have a significant positive relationship with price clustering at whole numbers.

\section{Unique issues in cryptocurrency markets}

As cryptocurrencies continue to develop they have merited the attention of policymakers and regulators for a host of differing reasons. However, there have been three specific situations that have been quite unique to cryptocurrency markets. The first is based on product sustainability which is being undermined as cryptocurrencies continue to grow due to the enormous electricity output that must be outlayed during the mining process. The second unique issue that we investigate is that of market correlations, which develops on earlier coverage of the diversification benefits of broad cryptocurrencies. The final issue investigated is the separation of commercial cryptocurrency usage to decipher as to whether there is a fundamental need for the use of cryptocurrencies or has the company attempted to take advantage of the hysteria around the new financial product for commercial gain. We examine this issue through the recent decision by Kodak to announce the Kodakcoin ICO.

\subsection{Sustainability}

The rapid growth of Bitcoin prices has attracted many investors from around the globe, generating not only an increase in mining difficulty but also pushing Bitcoin energy consumption to an enormous level. It is now becoming more difficult to find a new block and, consequentially, each transaction consumes more electricity now than it used to be in past. According to Bitcoin Sustainability Report in January 2018 Bitcoin energy consumption per one transaction increased on $53 \%$ and equal to $397 \mathrm{KWh}$, which is enough to power 
1 U.S. household for more than 13 days ${ }^{15}$. In February 2018 Bitcoin electricity consumption increased to $764 \mathrm{KWh}$ per unique transaction. The annual electricity consumption of Bitcoin increased from 9.5 TWh till 50.8 TWh in last 12 months, and In February 2018 Bitcoin consumes as much energy as Uzbekistan, representing $0.23 \%$ the world's electricity consumption. Similarly, the increase was evident for Ethereum from 2,3 TWh to 14.5 TWh per year ${ }^{16}$. While the issue of environmental sustainability of cryptocurrencies is under debate in the media (The Guardian, November 2017), academia has been relatively slow to address this urgent issue. Only a couple of papers discussed the impact of the growth of these digital asset classes on the environment. Sustainability in the context of environmental and economic aspects have been analysed by Vranken (2017), and the results provide an opposite conclusion to the popular belief. The paper claims that the energy consumption of mining Bitcoin is not excessive. One of the approaches used is a comparison of daily mining revenue and daily mining energy costs. When the mining revenue drop below mining cost miners has to switch to more efficient hardware, which encouraging continuous technological development.

\subsection{Market correlations}

While we have identified the key areas of research related to the role of cryptocurrencies as an alternative investment and source of diversification, there have been specific examples of dynamic correlations that merit special attention and further research. In early 2018 during the sharp collapse of Bitcoin as presented in Figure 3 there were three specific correlation events that merited attention: 1) market volatility was found to have transferred from stocks to broad cryptocurrencies; 2) a strong inverse correlation between cryptocurrencies and gold coin sales; and 3) correlations between cryptocurrencies depending on their flavour. Each of these individual cases merits the attention of regulators and policy-makers alike due to the potential contagion effects that could occur should cryptocurrencies continue to increase in price, or indeed collapse.

Intra-cryptocurrency volatility transfer and correlation effects were witnessed in January 2018. While the price of Bitcoin collapsed by approximately $\$ 10,000$ each, the correlations of different cryptocurrencies began to shift, presenting evidence that traders were beginning to make informed investment decisions based on the flavour of the cryptocurrency. As Bitcoin prices collapsed, short-term correlations with three specific altcoins began to change, namely IOTA, Litecoin and Bitcoin Cash. Both Litecoin and Bitcoin Cash are forks of Bitcoin designed to reduce friction to enable smaller everyday transactions which are susceptible to long processing times and high processing fees. IOTA, however, is designed for machineto-machine payments. The contrasting correlations of major cryptocurrencies and these three altcoins present evidence that cryptocurrency traders are making somewhat informed

\footnotetext{
${ }^{15}$ https: / digiconomist.net/bitcoin-sustainability-report-01-2018

${ }^{16}$ https://digiconomist.net/bitcoin-energy-consumption
} 
decisions. However, the correlations of broad cryptocurrencies are also somewhat damning as evident across a host of major international bubbles, including that of 'Tulipmania' ${ }^{17}$.

The year 2017 was found to be the least volatile year since 1964 with just $6.8 \%$ realised volatility for the S\&P 500 Index. Transfer of market volatility. Bitcoin, however, was over twelve times more volatile during the same time period. While many forces drive daily fluctuations in equities. There was a stability in stocks that stemmed from an especially strong consensus in late 2016 about the year ahead, which is further reflected in the relatively low levels of the Cboe Volatility Index (VIX) which is presented in Figure 5. It is such changes in the expectations of corporate earnings that have the most impact. For Bitcoin and other cryptocurrencies, this is not the case. For cryptocurrencies, there are no earnings and no consensus valuation frameworks, except for that which investor's place on the product. The rush to buy cryptocurrencies pushes prices higher, leading to a spiral of price volatility that is generated from the frenetic self-reinforcing momentum and speculative behaviour of cryptocurrency investors observed between 2014 and late-2017.

Dyhrberg et al. [2018] analyses Bitcoin market microstructure on three US cryptocurrency exchanges. Paper employs a high-frequency data intraday data of individual traders and quotes and suggest that most trades are non-algorithmic and executed by retail investors. The results also suggest that the volume of trading is positively correlated with volatility and negatively correlated with spreads. Using a number of Bitcoin transactions Koutmos [2018] found that a one standard deviation shock to transaction activity leads to just over a $0.30 \%$ gain in returns on the third day following the shock. However, the results report the reversal pattern by the sixth day after shock. The assessment of bidirectional linkages between Bitcoin returns and transaction activity show that the magnitude of spillovers from a return to transaction activity is larger than vice versa.

$\mathrm{Hu}$ et al. [2018] analysed intraday price behaviour of Bitcoin, Litecoin, and Ripple by examining the price clustering of non-fiat cryptocurrency exchange rate pairs. The findings report a significant price clustering at round numbers 00,000 , and 0000 providing support for negotiation hypothesis that predicts higher clustering for higher prices and price volatility. Hu et al. [2018] also found evidence of strategic trading in cryptocurrencies. Furthermore, Bouri et al. [2018] suggest the possibility to predict Bitcoin price movements

\footnotetext{
${ }^{17}$ Tulipmania was a period during which contract prices for some bulbs of the recently introduced and fashionable tulip reached extraordinarily high levels and then dramatically collapsed in February 1637. It is generally considered the first recorded speculative bubble. The theoretical development supporting the growth and development of bubbles has been covered in detail Blanchard [1979], Blanchard and Watson [1982], Evans [1991] and Bhattacharya and Yu [2008] among others. Bubbles are denoted as It is created by a surge in asset prices unwarranted by the fundamentals of the asset and driven by exuberant market behaviour. When investors are no longer willing to buy at the elevated price, a significant sell-off occurs, causing the bubble to blow up. This can sometimes be identified by stress metrics and indices. To date, the authors have not identified any research that traces the contagion of indexed cryptocurrency stress in a manner similar to Corbet and Twomey [2014] or Corbet [2014]. This would be considered to be an interesting avenue for future research.
} 
based on price information from the aggregate commodity index and gold prices, however authors suggest to use non-standard cointegration methods to analyse the relations between Bitcoin and other asset classes due to reported the asymmetry, non-linearity quantilesdependency of these relations. Finally, the analysis of 456 cryptocurrencies performed by Wei [2018] shows that return predictability diminishes in cryptocurrencies with high market liquidity, contributing to cryptocurrency efficiency and liquidity debates.

\section{Insert Figure 5 about here}

During the January 2018 Bitcoin price collapse, sales of gold coins spiked, indicating continued areas of inverse correlations. CoinInvest, an online gold dealer, claimed to have sold about $30 \mathrm{~kg}$ of gold coins worth over $\$ 1$ million on just the 16 of January as Bitcoin crashed by approximately $40 \%$. This reported level of trade was five times that of normal levels and was reported across a broad variety of online gold coin dealerships. This inverse correlation is reported to have been generated through an ability for cryptocurrency traders to cash out and buy physical gold. This inverse dynamic serves as another proof of a potential negative correlation between investors' interest towards gold and cryptocurrencies. Klein et al. [2018] compared Bitcoin to Gold and claim that Bitcoin acts in exact opposite manner in times of market distress. While gold can be effective hedge from a financial crisis due to the "flight-to-quality" behaviour of investors, Bitcoin is highly correlated with downwards markets. Therefore according to the results of Klein et al. [2018] Bitcoin is no hedge against equity investments. Selmi et al. [2018] compared the hedging properties of Bitcoin with Gold. The results are opposite to Klein et al. [2018] and suggest that both Gold and Bitcoin can be effective diversifier for investors during time of the economic and political turmoil. Furthermore, similarly to Gold Bitcoin can acts as a diversifier for oil price movements. According to Corbet et al. [2018] the introduction of Bitcoin futures and the ability to trade these would have resulted in a reduction in the variance of Bitcoin prices, or facilitated hedging strategies that could have mitigated pricing risk in the spot market, it is possible that the Bitcoin could have acted as a unit of account, moving it closer to being a currency.

\subsection{The curious Kodak case}

On the 9 of January 2018, camera manufacturer Kodak announced that it was entering the cryptocurrency market through the creation of KODAKOne, described as a revolutionary new image rights management and protection platform secured in the blockchain. Kodak announced that its development seamlessly registers, manages and monetizes creative assets for the photographic community (Corbet et al. [2018]). It would be used to underpin the assured buying and selling of rights-cleared and protected digital assets while ensuring transparency. Figure 6 presents the price, daily percentage volatility and a measure of news sentiment for Kodak (as measured by Google Trends data). It is immediately evident that 
the announcement had a significant sharp impact on volatility (which peaked at over $60 \%$ per day) with shares increasing from over $\$ 3$ per share to over $\$ 12$ in less than one week. This was associated with an increase in market sentiment and research using terms such as 'Kodak' and 'KODAKCoin'. Kodak CEO Jeff Clarke said in a press statement, 'For many in the technology industry, 'blockchain' and 'cryptocurrency' are hot buzzwords, but for photographers who've long struggled to assert control over their work and how it's used, these buzzwords are the keys to solving what felt like an unsolvable problem.' In theory, photographers will be able to upload their images to a platform called KodakOne, create a blockchain-based license for each image, and use web-crawling software to scour the internet looking for copyright violations. Instead of using dollars, photographers can have clients pay them in KODAKCoins. However, there are many analysts and market-commentators alike that continue to identify Kodak's strategy as a technique to capitalise on the current cryptocurrency frenzy or is it indeed a valid evolutionary characteristic of blockchain ${ }^{18}$.

\section{Insert Figure 6 about here}

These 'sudden' announcements have also attracted the attention of regulators. Jay Clayton, the chairman of the Securities and Exchange Commission (SEC), said that the agency was 'looking closely at the disclosures of public companies that shift their business models to capitalize on the perceived promise of distributed ledger technology.' However, Kodak then decided to delay the ICO of KODAKCoin in an attempt to verify accredited status of approximately 40,000 potential investors. The SEC requires that an individual accredited investor has a net worth that exceeds $\$ 1$ million, or an annual income of at least $\$ 200,000$, along with other conditions. The company claims it needs 'several weeks' to verify the 'accredited investors' status of those who applied to invest in the ICO. Potential investors from outside the US would then be considered in accordance with their local jurisdictions. But one key point that can be taken from the case of Kodak is that it's price, two months later, remained elevated by almost $100 \%$ of that from early January 2018. Even without the implementation of an ICO, the announcement of a cryptocurrency related plan has potentially incorporated any cryptocurrency speculation into the share price of a publicly traded company. This is a point of concern for regulators and policymakers alike.

\footnotetext{
${ }^{18}$ In August 2018, The Kodak-branded 'Kashminer' Bitcoin mining scheme collapsed, with Eastman Kodak distancing itself from the company behind it. This has led to some complications with the release of Kodakcoin, however, the company behind the Kashminer says that the US Securities and Exchanges Commission (SEC) had prevented the scheme from going ahead and is now hoping to establish a Bitcoin mining system in Iceland.
} 


\section{Concluding comments}

In this paper, we conduct a systematic analysis based on the growing breadth and depth of cryptocurrency research that has been published since 2009 up to August 2018. We acknowledge that this research field is immature, and new empirical and theoretical evidence continues to emerge on a monthly basis. Nevertheless, we document what is currently known about cryptocurrencies in the finance literature, whilst also providing real-life examples of ICOs and regulatory issues. We also explain the main limitations, as well as the concerns, with cryptocurrencies, as well as explain the regulatory issues that face governments and central banks alike. A limitation to our systematic analysis is the potential exclusion of some relevant studies that will become available during the publication process. However, we are quite confident that we have included the vast majority of the relevant, peer-reviewed studies, and we have updated this review during the revision process.

Our main findings demonstrate that there are numerous gaps in the cryptocurrency related literature. Although there are many potential areas of interest regarding cryptocurrencies, we identify ten important gaps in the literature in Table 5 which hopefully other researchers can use to further the knowledge in this area. While cryptocurrencies continue to develop both as a product and a traded-market, it is important that we moderate our expectations of their potential value and benefits to society while being cautious and considering towards the inherent dangers that they could generate within our society. Isolating lessons from our past, such as those found within 'Tulipmania' and the 'Dot-com' collapses contribute to the broad accusations of wider bubble-behaviour. But such accusations are directed in the knowledge that the future of finance and broad technology may lie in the underlying blockchain on which cryptocurrencies are based. 


\section{Bibliography}

Alvarez-Ramirez, J., E. Rodriguez, and C. Ibarra-Valdez (2018). Long-range correlations and asymmetry in the bitcoin market. Physica A: Statistical Mechanics and its Applications 492, 948-955.

Andrei, D. and M. Hasler (2014). Investor attention and stock market volatility. The review of financial studies 28(1), 33-72.

Ardia, D., K. Bluteau, and M. Ruede (2018). Regime changes in bitcoin garch volatility dynamics. Finance Research Letters (Forthcoming).

Atzori, M. (2015). Blockchain technology and decentralized governance: Is the state still necessary?

Baek, C. and M. Elbeck (2015). Bitcoins as an investment or speculative vehicle? a first look. Applied Economics Letters 22(1), 30-34.

Baker, M. and J. Wurgler (2007). Investor sentiment in the stock market. Journal of economic perspectives 21(2), 129-152.

Balcilar, M., E. Bouri, R. Gupta, and D. Roubaud (2017). Can volume predict bitcoin returns and volatility? a quantiles-based approach. Economic Modelling 64, 74-81.

Bariviera, A. F., M. J. Basgall, W. Hasperué, and M. Naiouf (2017). Some stylized facts of the bitcoin market. Physica A: Statistical Mechanics and its Applications 484, 82-90.

Baur, D. G., T. Dimpfl, and K. Kuck (2017). Bitcoin, gold and the us dollar-a replication and extension. Finance Research Letters.

Baur, D. G., K. Hong, and A. D. Lee (2017). Bitcoin: Medium of exchange or speculative assets? Journal of International Financial Markets, Institutions and Money.

Bhattacharya, U. and X. Yu (2008). The causes and consequences of recent financial market bubbles: An introduction. The Review of Financial Studies 21(1), 3-10.

Blanchard, O. J. (1979). Speculative bubbles, crashes and rational expectations. Economics letters 3(4), 387-389.

Blanchard, O. J. and M. W. Watson (1982). Bubbles, rational expectations and financial markets.

Blau, B. M. (2018). Price dynamics and speculative trading in bitcoin. Research in International Business and Finance 43, 15-21.

Böhme, R., N. Christin, B. Edelman, and T. Moore (2015). Bitcoin: Economics, technology, and governance. Journal of Economic Perspectives 29(2), 213-38.

Bollen, R. (2013). The legal status of online currencies: are bitcoins the future? SSRN.

Bouoiyour, J. and R. Selmi (2015). What does bitcoin look like? Annals of Economics \&5 Finance 16(2). 
Bouri, E., R. Gupta, A. Lahiani, and M. Shahbaz (2018). Testing for asymmetric nonlinear shortand long-run relationships between bitcoin, aggregate commodity and gold prices. Resource Policy 57, 224-235.

Bouri, E., R. Gupta, and D. Roubaud (2018). Herding behaviour in cryptocurrencies. Finance Research Letters (Forthcoming).

Bouri, E., R. Gupta, A. K. Tiwari, and D. Roubaud (2017). Does bitcoin hedge global uncertainty? evidence from wavelet-based quantile-in-quantile regressions. Finance Research Letters 23, 87-95.

Bouri, E., P. Molnár, G. Azzi, D. Roubaud, and L. I. Hagfors (2017). On the hedge and safe haven properties of bitcoin: Is it really more than a diversifier? Finance Research Letters 20, 192-198.

Bouri, E., S. Shahzad, and D. Roubaud (2018). Co-explosivity in the cryptocurrency market. Finance Research Letters (Forthcoming).

Brauneis, A. and R. Mestel (2018a). Cryptocurrency-portfolios in a mean-variance framework. Finance Research Letters Forthcoming.

Brauneis, A. and R. Mestel (2018b). Price discovery of cryptocurrencies: Bitcoin and beyond. Economics Letters.

Brière, M., K. Oosterlinck, and A. Szafarz (2015). Virtual currency, tangible return: Portfolio diversification with bitcoin. Journal of Asset Management 16(6), 365-373.

Brito, J., H. Shadab, and A. Castillo (2014). Bitcoin financial regulation: Securities, derivatives, prediction markets, and gambling+. Colum. Sci. \& Tech. L. Rev. 16, 146-452.

Caporale, G. M., L. Gil-Alana, and R. Mestel (2018). Persistence in the cryptocurrency market. Research in International Business and Finance forthcoming.

Charfeddine, L. and Y. Maouchi (2018). Are shocks on the returns and volatility of cryptocurrencies really persistent? Finance Research Letters (Forthcoming).

Cheah, E.-T. and J. Fry (2015). Speculative bubbles in bitcoin markets? an empirical investigation into the fundamental value of bitcoin. Economics Letters 130, 32-36.

Cheah, E.-T., T. Mishra, M. Parhi, and Z. Zhang (2018). Long memory interdependency and inefficiency in bitcoin markets. Economics Letters X, X.

Cheung, A., E. Roca, and J.-J. Su (2015). Crypto-currency bubbles: an application of the phillipsshi-yu (2013) methodology on mt. gox bitcoin prices. Applied Economics 47(23), 2348-2358.

Ciaian, P., M. Rajcaniova, et al. (2018). Virtual relationships: Short-and long-run evidence from bitcoin and altcoin markets. Journal of International Financial Markets, Institutions and Money 52, $173-195$.

Corbet, S. (2014). The european financial market stress index. International Journal of Economics and Financial Issues 4 (1), 217-230. 
Corbet, S., C. Larkin, B. Lucey, A. Meegan, and L. Yarovaya (2018a). Exploring the dynamic relationships between cryptocurrencies and other financial assets. Economics Letters 165(1), $28-34$.

Corbet, S., C. Larkin, B. Lucey, and L. Yaravaya (2018). Kodakcoin: A blockchain revolution or exploiting a potential cryptocurrency bubble? Available at https://ssrn. com/abstract=3140551.

Corbet, S., C. J. Larkin, B. M. Lucey, A. Meegan, and L. Yarovaya (2018b). The volatility generating effects of macroeconomic news on cryptocurrency returns. Available at SSRN: https://ssrn.com/abstract=3073727.

Corbet, S., B. Lucey, M. Peat, and S. Vigne (2018). Bitcoin futures - what use are they? Economics Letters (Forthcoming).

Corbet, S., B. Lucey, and L. Yarovya (2017). Datestamping the Bitcoin and Ethereum bubbles. Finance Research Letters, forthcoming.

Corbet, S., G. McHugh, and A. Meegan (2017). The influence of central bank monetary policy announcements on cryptocurrency return volatility. Investment Management and Financial Innovations 14(4), 60-72.

Corbet, S. and C. Twomey (2014). An index of financial market stress for the united kingdom. Economics and Business Letters 3(2), 127-133.

Delgado-Segura, S., C. Pérez-Sola, G. Navarro-Arribas, and J. Herrera-Joancomartí (2017). A fair protocol for data trading based on bitcoin transactions. Future Generation Computer Systems.

Demir, E., G. Gozgor, C. K. M. Lau, and S. A. Vigne (2018). Does economic policy uncertainty predict the bitcoin returns? an empirical investigation. Finance Research Letters.

Diebold, F. X. and R. S. Mariano (2002). Comparing predictive accuracy. Journal of Business E economic statistics 20(1), 134-144.

Dwyer, G. P. (2015). The economics of bitcoin and similar private digital currencies. Journal of Financial Stability 17, 81-91.

Dyhrberg, A., S. Foley, and J. Svec (2018). How investible is bitcoin? analyzing the liquidity and transaction costs of bitcoin markets. Economics Letters 17, 140-143.

Dyhrberg, A. H. (2016a). Bitcoin, gold and the dollar-a garch volatility analysis. Finance Research Letters 16, 85-92.

Dyhrberg, A. H. (2016b). Hedging capabilities of bitcoin. is it the virtual gold? Finance Research Letters 16, 139-144.

Evans, G. W. (1991). Pitfalls in testing for explosive bubbles in asset prices. The American Economic Review 81(4), 922-930.

Fry, J. (2018). Booms, busts and heavy-tails: The story of bitcoin and cryptocurrency markets? Economics Letters 17, 225-229. 
Fry, J. and E.-T. Cheah (2016). Negative bubbles and shocks in cryptocurrency markets. International Review of Financial Analysis 47, 343-352.

Gandal, N., J. Hamrick, T. Moore, and T. Oberman (2018). Price manipulation in the bitcoin ecosystem. Journal of Monetary Economics.

Giudici, P. and I. Abu-Hashish (2018). What determines bitcoin exchange prices? a network var approach. Finance Research Letters (Forthcoming).

Gkillas, K. and P. Katsiampa (2018). An application of extreme value theory to cryptocurrencies. Economics Letters 164(1), 109-111.

Glaser, F., K. Zimmermann, M. Haferkorn, M. Weber, and M. Siering (2014). Bitcoin-asset or currency? revealing users' hidden intentions.

Göbel, J., H. P. Keeler, A. E. Krzesinski, and P. G. Taylor (2016). Bitcoin blockchain dynamics: The selfish-mine strategy in the presence of propagation delay. Performance Evaluation 104, $23-41$.

Gramoli, V. (2017). From blockchain consensus back to byzantine consensus. Future Generation Computer Systems.

Grinberg, R. (2012). Bitcoin: An innovative alternative digital currency. Hastings Sci. \&6 Tech. LJ 4,159 .

Gross, A., J. Hemker, J. Hoelscher, and B. Reed (2017). The role of secondary sources on the taxation of digital currency (bitcoin) before irs guidance was issued. Journal of Accounting Education 39, 48-54.

Guesmi, K., S. Saadi, I. Abid, and Z. Ftiti (2018). Portfolio diversification with virtual currency: Evidence from bitcoin. International Review of Financial Analysis (Forthcoming).

Hansen, P. R., A. Lunde, and J. M. Nason (2011). The model confidence set. Econometrica 79(2), 453-497.

Harvey, C. R. (2014). Bitcoin myths and facts.

Hendrickson, J. R. and W. J. Luther (2017). Banning bitcoin. Journal of Economic Behavior E Organization 141, 188-195.

Houy, N. (2014). It will cost you nothing to 'kill' a proof-of-stake cryptocurrency.

Hu, B., T. McInish, J. Miller, and L. Zeng (2018). Intraday price behavior of cryptocurrencies. Finance Research Letters (Forthcoming).

Huang, H., X. Chen, Q. Wu, X. Huang, and J. Shen (2018). Bitcoin-based fair payments for outsourcing computations of fog devices. Future Generation Computer Systems 78, 850-858.

Jang, H. and J. Lee (2017). An empirical study on modeling and prediction of bitcoin prices with bayesian neural networks based on blockchain information. IEEE Access. 
Ji, Q., E. Bouri, R. Gupta, and D. Roubaud (2018). Network causality structures among bitcoin and other financial assets: A directed acyclic graph approach. The Quarterly Review of Economics and Finance Forthcoming.

Jiang, Y., H. Nie, and W. Ruan (2017). Time-varying long-term memory in bitcoin market. Finance Research Letters.

Khuntia, S. and J. Pattanayak (2018). Adaptive market hypothesis and evolving predictability of bitcoin. Economics Letters 167, $26-28$.

Klein, T., H. Thu, and T. Walther (2018). Bitcoin is not the new gold - a comparison of volatility, correlation, and portfolio performance. International Review of Financial Analysis 59, 105-116.

Koutmos, D. (2018). Bitcoin returns and transaction activity. Economics Letters 167, 81-85.

Lagoarde-Segot, T. (2015). Diversifying finance research: From financialization to sustainability. International Review of Financial Analysis 39, 1-6.

Lahmiri, S. and S. Bekiros (2018). Chaos, randomness and multi-fractality in bitcoin market. Chaos, Solitons 83 Fractals 106, 28-34.

Li, X., P. Jiang, T. Chen, X. Luo, and Q. Wen (2017). A survey on the security of blockchain systems. Future Generation Computer Systems.

Liu, W. (2018). Portfolio diversification across cryptocurrencies. Finance Research Letters (Forthcoming).

Lucey, B. M., S. A. Vigne, L. Ballester, L. Barbopoulos, J. Brzeszczynski, O. Carchano, N. Dimic, V. Fernandez, F. Gogolin, A. González-Urteaga, J. W. Goodell, P. Helbing, R. Ichev, F. Kearney, E. Laing, C. J. Larkin, A. Lindblad, I. Lončarski, K. C. Ly, M. Marinč, R. J. McGee, F. McGroarty, C. Neville, M. O'Hagan-Luff, V. Piljak, A. Sevic, X. Sheng, D. Stafylas, A. Urquhart, R. Versteeg, A. N. Vu, S. Wolfe, L. Yarovaya, and A. Zaghini (2018). Future directions in international financial integration research - A crowdsourced perspective. International Review of Financial Analysis 55, 35-49.

Luther, W. J. (2016). Bitcoin and the future of digital payments. The Independent Review 20(3), 397-404.

Luther, W. J. and A. W. Salter (2017). Bitcoin and the bailout. The Quarterly Review of Economics and Finance 66, 50-56.

Maesa, D. D. F., A. Marino, and L. Ricci (2017). Detecting artificial behaviours in the bitcoin users graph. Online Social Networks and Media 3, 63-74.

Mai, F., Q. Bai, Z. Shan, X. Wang, and R. Chiang (2015). From bitcoin to big coin: The impacts of social media on bitcoin performance. SSRN Electronic Journal.

Marian, O. (2013). Are cryptocurrencies super tax havens? Michigan Law Review First Impressions 112(1), 38-48. 
Mensi, W., K. Al-Yahyaee, and S. Kang (2018). Structural breaks and double long memory of cryptocurrency prices: A comparative analysis from bitcoin and ethereum. Finance Research Letters (Forthcoming).

Nadarajah, S. and J. Chu (2017). On the inefficiency of bitcoin. Economics Letters 150, 6-9.

Nakamoto, S. (2008). Bitcoin: A peer-to-peer electronic cash system. Available at https://Bitcoin.org/Bitcoin.pdf.

O'Connor, F. A., B. M. Lucey, J. A. Batten, and D. G. Baur (2015). The financial economics of goldâĂTa survey. International Review of Financial Analysis 41, 186-205.

Peng, Y., P. H. M. Albuquerque, J. M. C. de Sá, A. J. A. Padula, and M. R. Montenegro (2018). The best of two worlds: Forecasting high frequency volatility for cryptocurrencies and traditional currencies with support vector regression. Expert Systems with Applications 97, 177-192.

Phillip, A., J. Chan, and S. Peiris (2018). A new look at cryptocurrencies. Economics Letters 163, 6-9.

Phillips, P. C., S. Shi, and J. Yu (2015). Testing for multiple bubbles: Historical episodes of exuberance and collapse in the s\&p 500. International Economic Review 56(4), 1043-1078.

Phillips, P. C., Y. Wu, and J. Yu (2011). Explosive behavior in the 1990s nasdaq: When did exuberance escalate asset values? International Economic Review 52(1), 201-226.

Pieters, G. and S. Vivanco (2017). Financial regulations and price inconsistencies across bitcoin markets. Information Economics and Policy 39, 1-14.

Pinzón, C. and C. Rocha (2016). Double-spend attack models with time advantange for bitcoin. Electronic Notes in Theoretical Computer Science 329, 79-103.

Platanakis, E., C. Sutcliffe, and A. Urquhart (2018). Optimal vs naïve diversification in cryptocurrencies. Economics Letters 171, $93-96$.

Platanakis, E. and A. Urquhart (2018). Should investors include bitcoin in their portfolios? A portfolio theory approach. SSRN Available at: https://ssrn.com/abstract=3215321 or http://dx.doi.org/10.2139/ssrn.3215321.

Polasik, M., A. I. Piotrowska, T. P. Wisniewski, R. Kotkowski, and G. Lightfoot (2015). Price fluctuations and the use of bitcoin: An empirical inquiry. International Journal of Electronic Commerce 20(1), 9-49.

Prybila, C., S. Schulte, C. Hochreiner, and I. Weber (2017). Runtime verification for business processes utilizing the bitcoin blockchain. Future Generation Computer Systems.

Rohr, J. and A. Wright (2017). Blockchain-based token sales, initial coin offerings, and the democratization of public capital markets.

Roth, N. (2015). An architectural assessment of bitcoin: using the systems modeling language. Procedia Computer Science 44, 527-536. 
Savelyev, A. (2017). Copyright in the blockchain era: Promises and challenges. Computer Law $\mathscr{E}$ Security Review.

Selgin, G. (2015). Synthetic commodity money. Journal of Financial Stability 17, 92-99.

Selmi, R., W. Mensi, S. Hammoudeh, and J. Bouoiyour (2018). Is bitcoin a hedge, a safe haven or a diversifier for oil pricemovements? a comparison with gold. Energy Economics 74, 787-801.

Sensoy, A. (2018). The inefficiency of bitcoin revisited: A high-frequency analysis with alternative currencies. Finance Research Letters.

Shiller, R. C. (2000). Irrational exuberance. Philosophy 83 Public Policy Quarterly 20(1), 18-23.

Takaishi, T. and T. Adachi (2018). Taylor effect in bitcoin time series. Economics Letters 172, 5-7.

Tasca, P., A. Hayes, and S. Liu (2016). The evolution of the bitcoin economy: extracting and analyzing the network of payment relationships. The Journal of Risk Finance (just-accepted), $00-00$.

Thies, S. and P. Molnar (2018). Bayesian change point analysis of bitcoin returns. Finance Research Letters (Forthcoming).

Tiwari, A. K., R. Jana, D. Das, and D. Roubaud (2018). Informational efficiency of bitcoinâĂ ̌̆an extension. Economics Letters 163, 106-109.

Trautman, L. (2013). Virtual currencies: Bitcoin \& what now after liberty reserve, silk road, and mt. gox. Rich. JL \& Tech. 20,1.

Turk, Ž. and R. Klinc (2017). Potentials of blockchain technology for construction management. Procedia Engineering 196, 638-645.

Urquhart, A. (2016). The inefficiency of bitcoin. Economics Letters 148, 80-82.

Urquhart, A. (2017). Price clustering in bitcoin. Economics Letters 159, 145-148.

Urquhart, A. (2018). What causes the attention of bitcoin? Economics Letters 166, 40-44.

Urquhart, A. and H. Zhang (2018). Is bitcoin a hedge or safe-haven for currencies? An intraday analysis. Available at SSRN: https://ssrn.com/abstract=3114108.

Vandezande, N. (2017). Virtual currencies under eu anti-money laundering law. Computer Law $\mathscr{E}$ Security Review 33(3), 341-353.

Vidal-Tomás, D. and A. Ibañez (2018). Semi-strong efficiency of bitcoin. Finance Research Letters.

Viglione, R. (2015). Does governance have a role in pricing? cross-country evidence from bitcoin markets.

Vigne, S. A., B. M. Lucey, F. A. OâĂŹConnor, and L. Yarovaya (2017). The financial economics of white precious metalsâĂTa survey. International Review of Financial Analysis 52, 292-308. 
Vranken, H. (2017). Sustainability of bitcoin and blockchains. Current Opinion in Environmental Sustainability 28, 1-9.

Wang, H., D. He, and Y. Ji (2017). Designated-verifier proof of assets for bitcoin exchange using elliptic curve cryptography. Future Generation Computer Systems.

Weber, B. (2014). Bitcoin and the legitimacy crisis of money. Cambridge Journal of Economics $40(1), 17-41$.

Wei, W. C. (2018). Liquidity and market efficiency in cryptocurrencies. Economics Letters 168, $21-24$.

Zimba, A., Z. Wang, and H. Chen (2018). Multi-stage crypto ransomware attacks: A new emerging cyber threat to critical infrastructure and industrial control systems. ICT Express. 
Figure 1: Duration of data coverage for incorporated quantitative cryptocurrency based literature

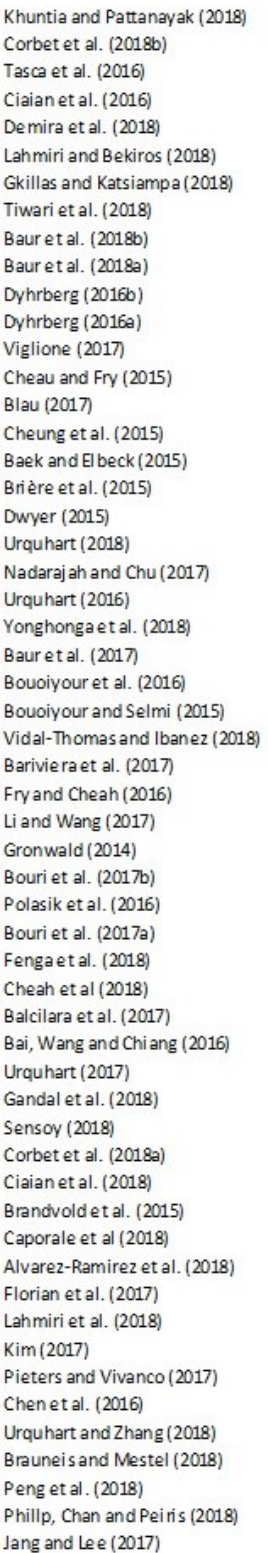

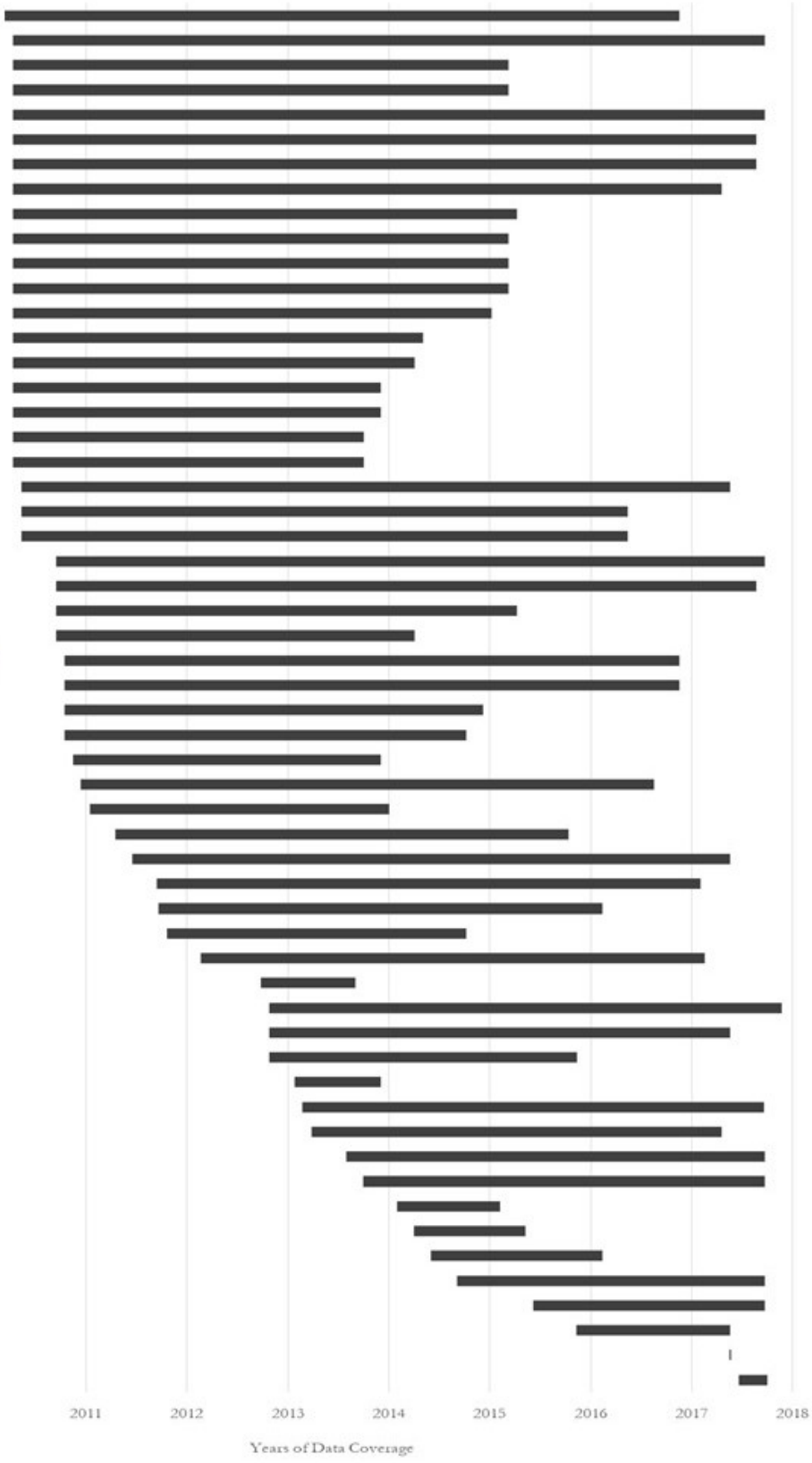

Note: The above figure presents a visual representation of the data that has been included in the incorporated cryptocurrency research. Where multiple samples are included in the research, the presented data coverage is that based on the key results of the included research. 
Figure 2: Frequency of cryptocurrency selection as central topic of investigation

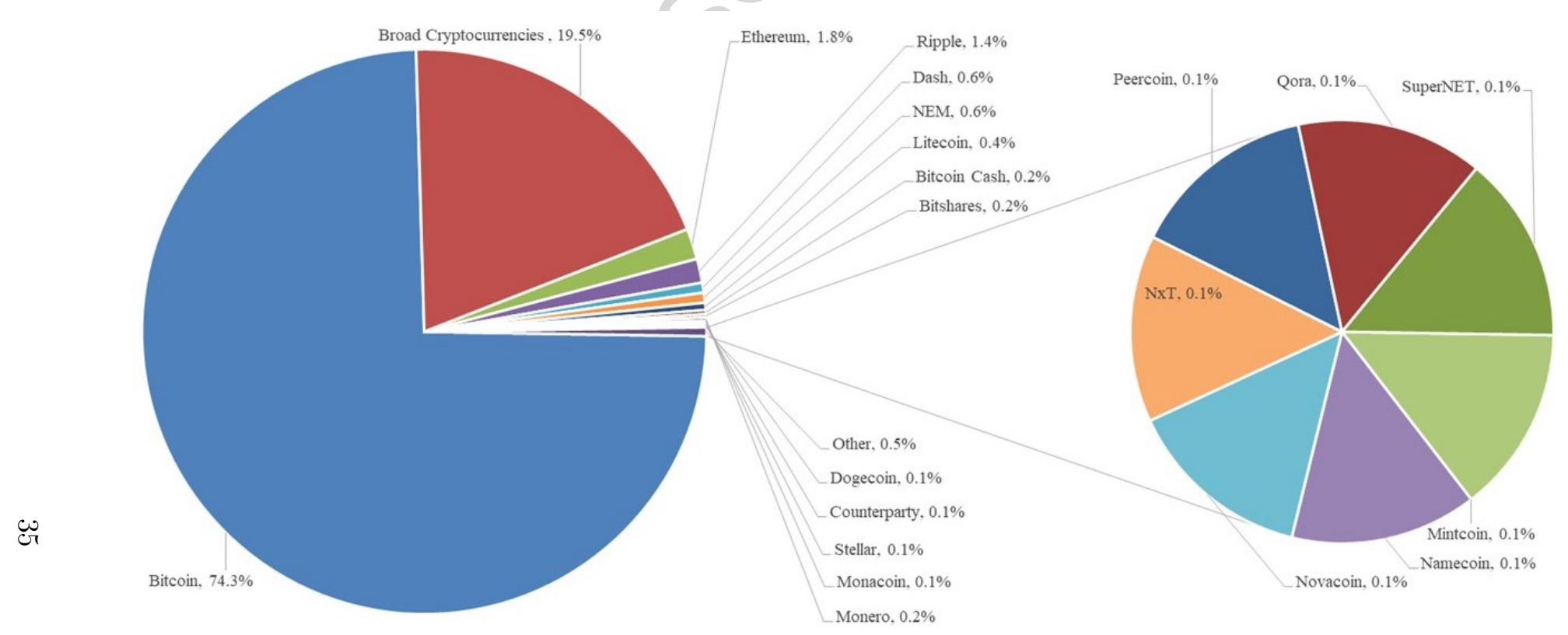

Note: The above figure presents the frequency of selection (measured as a percentage) of cryptocurrencies as a central topic of investigation within the research that has been selected for use in our systematic analysis. 
Figure 3: Bitcoin price level and daily price volatility (2010-2018)

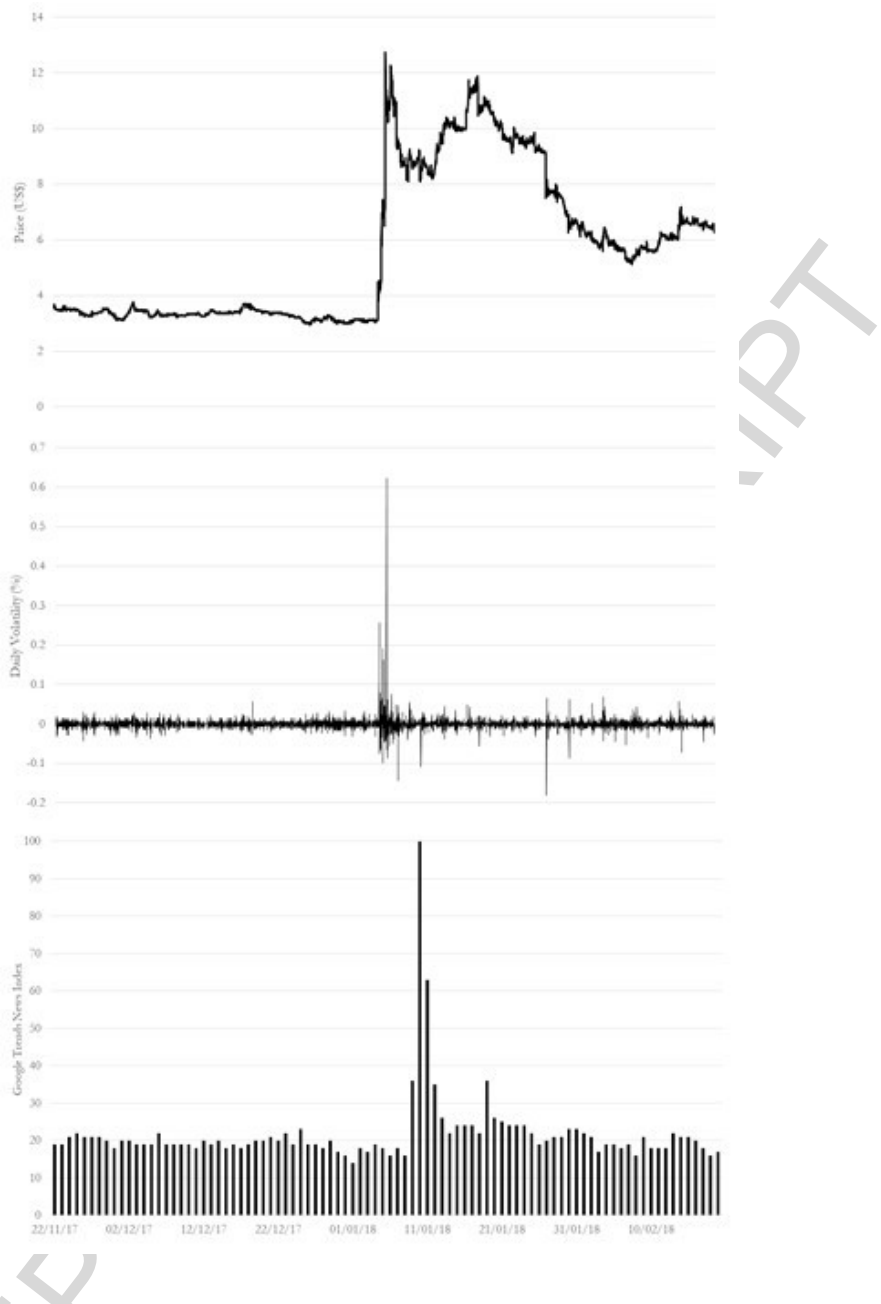

Note: The above panel represents the price of Bitcoin in US\$. The bottom panel represents represents the daily percentage volatility of Bitcoin returns. 
Figure 4: The Cryptocurrency Trilemma

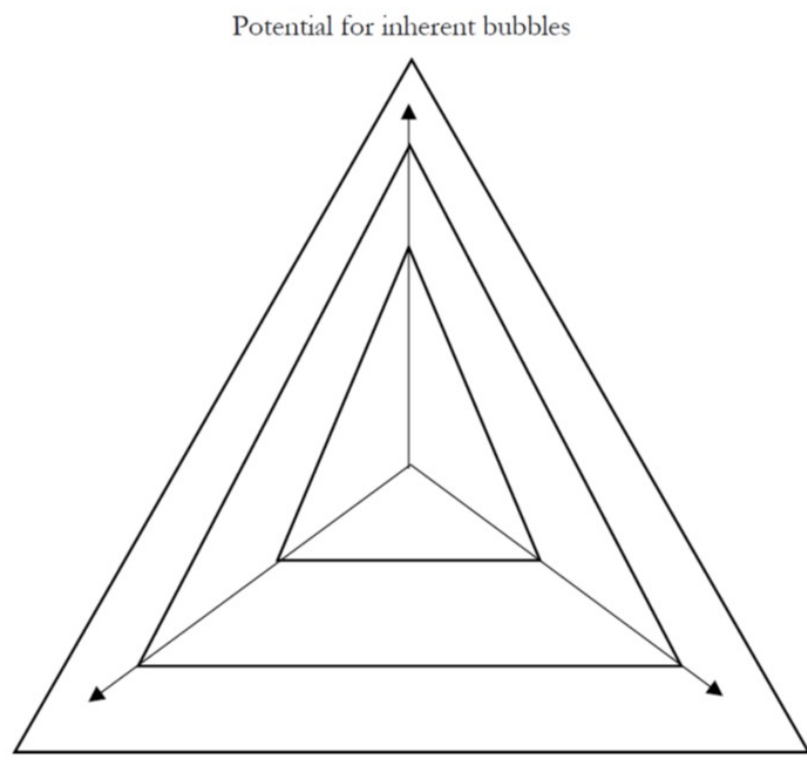

Regulatory alignment

Cybercriminality

Note: This trilemma develops on the three key interrelated issues that cryptocurrencies must be overcome and are each considered in Sections 2.2, 2.3 and 2.4. While there have been significant declines in the price of Bitcoin associated with rumours of regulatory imposition, even the widespread banning of cryptocurrencies in some jurisdictions, the easing of such regulatory pressures should theoretically generate substantial price appreciation. Further, the growth of significant episodes of cybercrime continues to undermine confidence and stability in the cryptocurrency market with significant consequences. However, the presence of inherent pricing bubbles generate substantial rewards for those who wish to profit from such illicit tactics as cryptocurrency market hacking a theft. Growth in cybercrime also generates an immediate need for improved international regulatory alignment, but is also associated with the widespread banning of such financial instruments in some jurisdictions, therefore further misalignment of the international regulatory approach. 


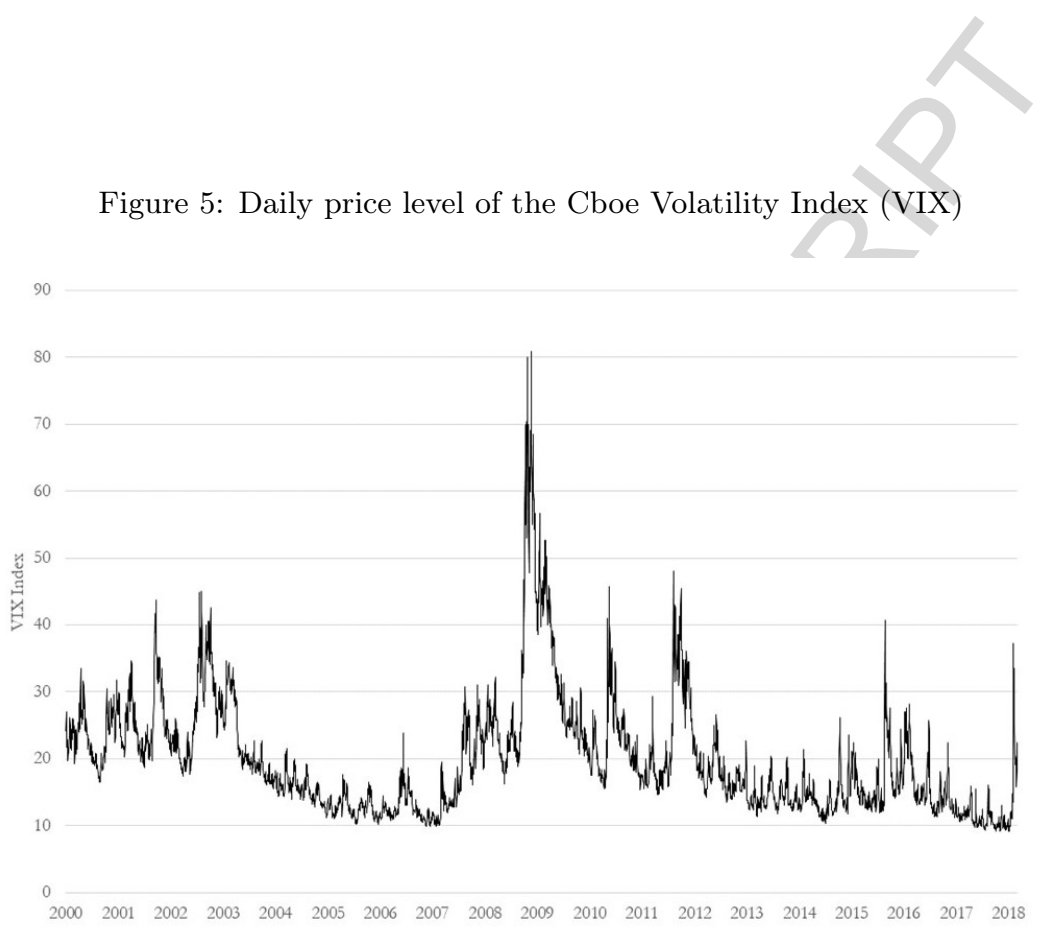

Note: The CBOE Volatility Index, known by its ticker symbol VIX, is a popular measure of the stock market's expectation of volatility implied by S\&P 500 index options, calculated and published by the Chicago Board Options Exchange (CBOE). It is colloquially referred to as the fear index or the fear gauge. 
Figure 6: Share price, price volatility and news dissemination for Kodak between November 2017 and February 2018

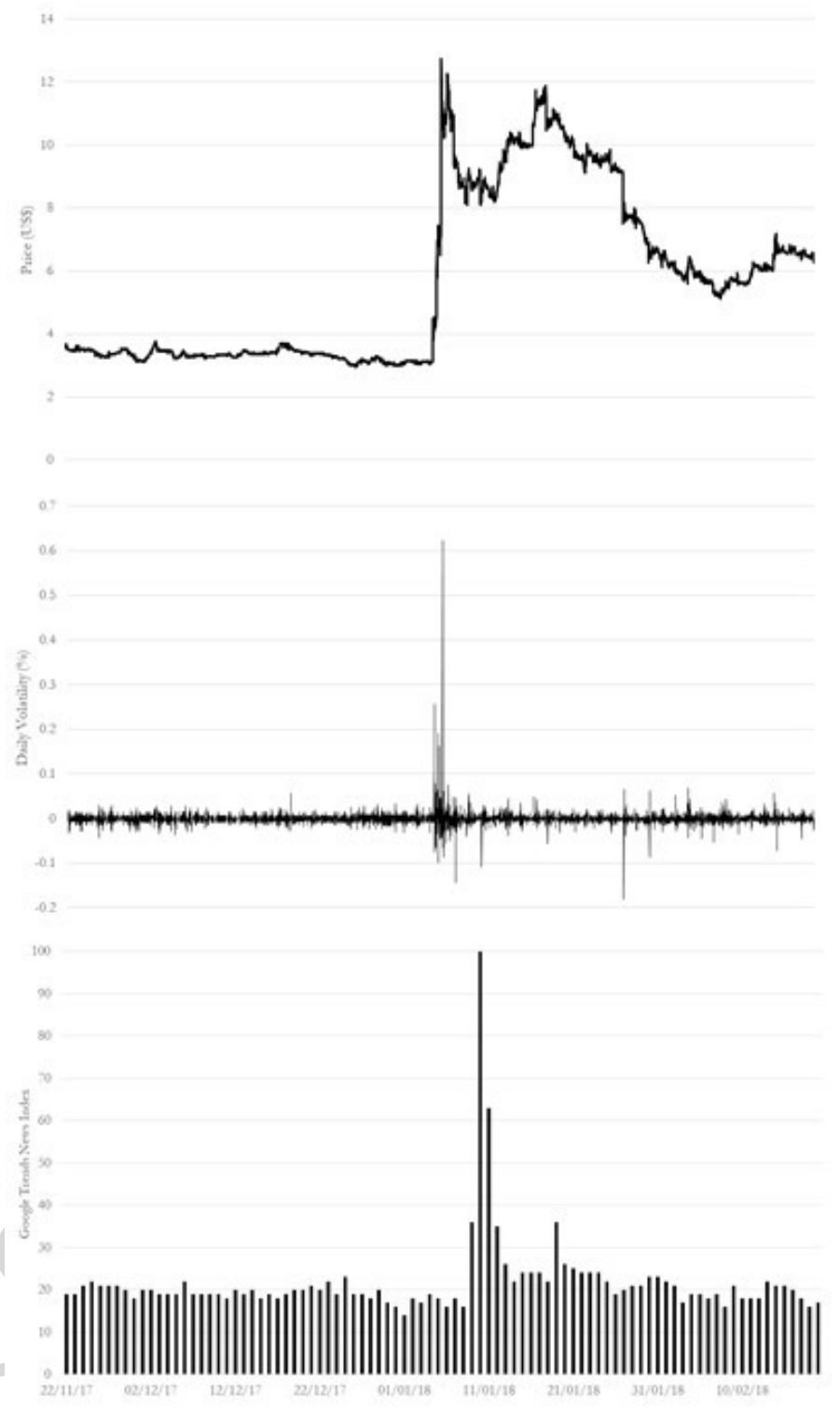

Note: The top panel represents the share price of Kodak shares in US\$. The middle panel represents the daily price volatility of Kodak, measured as daily percentage change. The lower panel represents the indexed level of investigation of the term 'Kodak' as presented with data from Google Trends as investigated in Corbet et al. [2018]. 
Table 1: Key characteristics of included non-quantitative research

\begin{tabular}{|c|c|c|c|c|c|c|}
\hline Paper & Name & Authors & Year & Journal & Broad Coverage & $\begin{array}{l}\text { Central Topic of } \\
\text { Literature }\end{array}$ \\
\hline${ }_{1}^{\text {Bub }}$ & $\begin{array}{l}\text { e Dynamics } \\
\text { Sustainability of bitcoin and } \\
\text { blockchains }\end{array}$ & Vranken & 2017 & $\begin{array}{l}\text { Current Opinion in En- } \\
\text { vironmental Sustainabil- } \\
\text { ity }\end{array}$ & $\begin{array}{l}\text { Literature and Ex- } \\
\text { planation }\end{array}$ & $\begin{array}{l}\text { Cryptocurrency } \\
\text { Structure }\end{array}$ \\
\hline \multicolumn{7}{|c|}{ Regulation } \\
\hline 2 & $\begin{array}{l}\text { Bitcoin: An Innovative Alternative } \\
\text { Digital Currency }\end{array}$ & Grinberg & 2011 & Working Paper & Literature Review & Bitcoin Status \\
\hline 3 & $\begin{array}{l}\text { The legal status of online currencies: } \\
\text { Are Bitcoins the future? }\end{array}$ & Bollen & 2013 & Working Paper & Literature & $\begin{array}{l}\text { Overview of Legal } \\
\text { Structure }\end{array}$ \\
\hline 4 & $\begin{array}{l}\text { It will cost you nothing to kill a Proof } \\
\text { of Stake cryptocurrency }\end{array}$ & Houy & 2014 & Working Paper & $\begin{array}{l}\text { Theoretical Struc- } \\
\text { ture }\end{array}$ & theoretical \\
\hline 5 & $\begin{array}{l}\text { Bitcoin financial regulation: Securities, } \\
\text { derivatives, prediction markets and } \\
\text { gambling }\end{array}$ & Brito et al. & 2014 & $\begin{array}{l}\text { Columbia Science and } \\
\text { Technology Law Review }\end{array}$ & Literature Review & How to regulate \\
\hline 6 & $\begin{array}{l}\text { Bitcoin: Economics, Technology, and } \\
\text { Governance }\end{array}$ & Bohme et al. & 2015 & $\begin{array}{l}\text { Journal of Economic } \\
\text { Perspectives }\end{array}$ & Literature & Regulation \\
\hline 7 & $\begin{array}{l}\text { Blockchain Technology and Decentral- } \\
\text { ized Governance: Is the State Still Nec- } \\
\text { essary? }\end{array}$ & Atzori & 2015 & Working Paper & None & Regulation \\
\hline 8 & $\begin{array}{l}\text { The role of secondary sources on the } \\
\text { taxation of digital currency (Bitcoin) } \\
\text { before IRS guidance was issued }\end{array}$ & $\begin{array}{l}\text { Andrew Gross } \\
\text { et al. }\end{array}$ & 2017 & $\begin{array}{l}\text { Journal of Accounting } \\
\text { Education }\end{array}$ & $\begin{array}{l}\text { Theoretical } \\
\text { ture }\end{array}$ & Bitcoin taxation \\
\hline 9 & $\begin{array}{l}\text { Are Cryptocurrencies super tax } \\
\text { havens? }\end{array}$ & Marian & 2017 & Working Paper & $\begin{array}{l}\text { Theoretical } \\
\text { ture }\end{array}$ & Tax Status \\
\hline 10 & Banning Bitcoin & $\begin{array}{l}\text { Hendrickson } \\
\text { and Luther }\end{array}$ & 2017 & $\begin{array}{l}\text { Journal of Economic Be- } \\
\text { havior \& Organization }\end{array}$ & $\begin{array}{l}\text { Theoretical Struc- } \\
\text { ture }\end{array}$ & Regulation \\
\hline 11 & $\begin{array}{l}\text { Copyright in the blockchain era: } \\
\text { Promises and challenges }\end{array}$ & Savelyev & 2017 & $\begin{array}{l}\text { Computer Law and Se- } \\
\text { curity Review }\end{array}$ & Literature Review & $\begin{array}{l}\text { Legal reform for } \\
\text { copyright }\end{array}$ \\
\hline 12 & $\begin{array}{l}\text { Blockchain-Based Token Sales, Initial } \\
\text { Coin Offerings, and the Democratiza- } \\
\text { tion of Public Capital Markets }\end{array}$ & $\begin{array}{l}\text { Rohr } \\
\text { Wright }\end{array}$ & 2017 & Working Paper & None & Regulation \\
\hline
\end{tabular}


Table 1: Key characteristics of included non-quantitative research

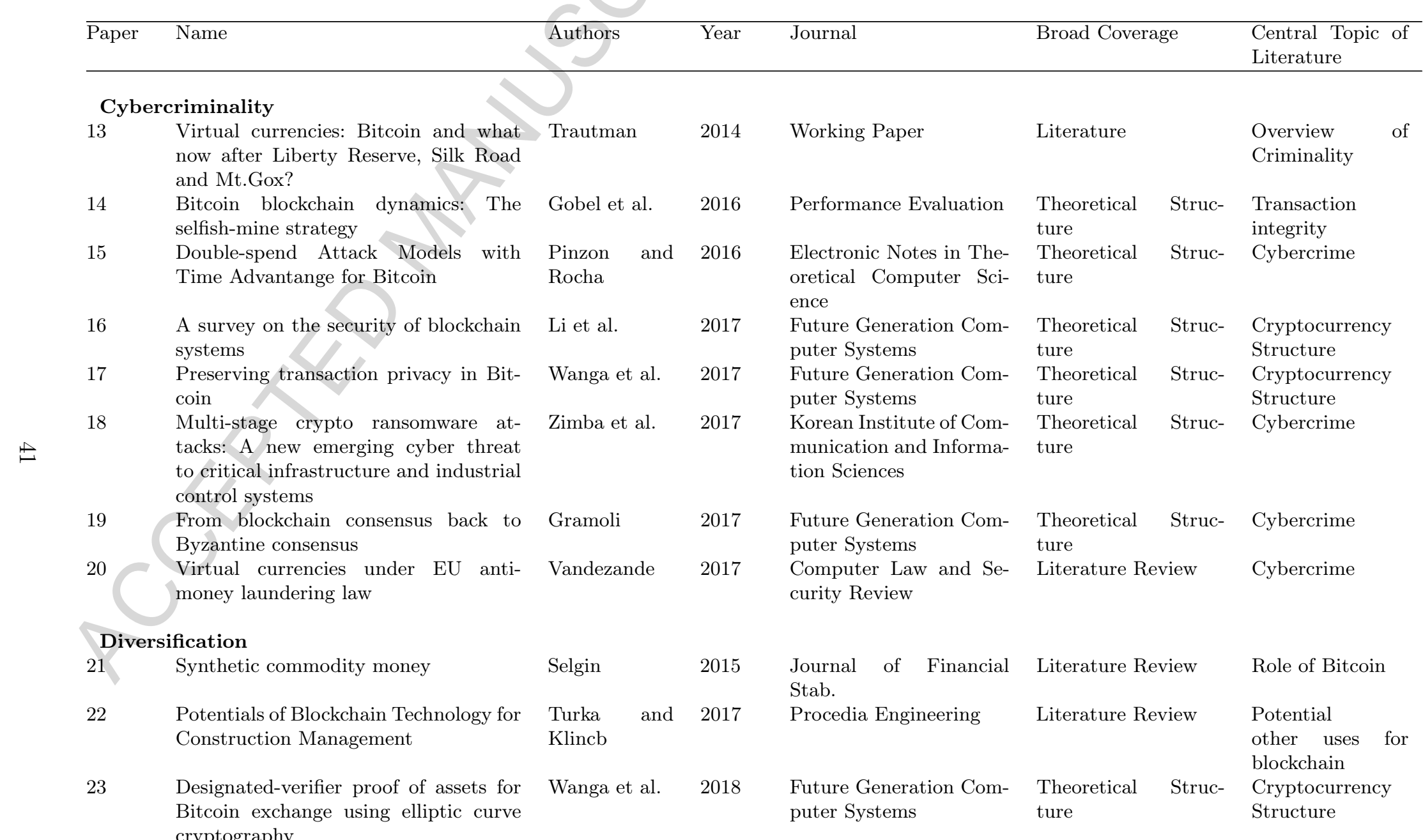


Table 1: Key characteristics of included non-quantitative research

\begin{tabular}{|c|c|c|c|c|c|c|c|}
\hline Paper & Name & Authors & Year & Journal & \multicolumn{2}{|c|}{ Broad Coverage } & $\begin{array}{l}\text { Central Topic of } \\
\text { Literature }\end{array}$ \\
\hline \multicolumn{8}{|c|}{ Efficiency } \\
\hline 24 & $\begin{array}{l}\text { The economics of Bitcoin transaction } \\
\text { fees }\end{array}$ & Houy & 2014 & Working Paper & $\begin{array}{l}\text { Theoretical } \\
\text { ture }\end{array}$ & Struc- & Cost of Bitcoin \\
\hline 25 & $\begin{array}{l}\text { Analyzing the deployment of Bitcoin's } \\
\text { P2P network under an AS-level per- } \\
\text { spective }\end{array}$ & Feld et al. & 2014 & $\begin{array}{l}\text { Procedia Computer Sci- } \\
\text { ence }\end{array}$ & P2P Routes & & $\begin{array}{l}\text { Market Distribu- } \\
\text { tion }\end{array}$ \\
\hline 26 & Bitcoin Myths and Facts & Harvey & 2014 & Working Paper & \multicolumn{2}{|c|}{ Literature Review } & $\begin{array}{l}\text { Fact and Fiction } \\
\text { of Bitcoin }\end{array}$ \\
\hline 27 & An Architectural Assessment of Bitcoin & Roth & 2015 & $\begin{array}{l}\text { Procedia Computer Sci- } \\
\text { ence }\end{array}$ & \multicolumn{2}{|l|}{ None } & theoretical \\
\hline 28 & $\begin{array}{l}\text { Bitcoin and the Future of Digital Pay- } \\
\text { ments }\end{array}$ & Luther & 2016 & The Independent Review & \multicolumn{2}{|c|}{ Literature Review } & $\begin{array}{l}\text { Future of Digital } \\
\text { Payments }\end{array}$ \\
\hline 29 & $\begin{array}{l}\text { A fair protocol for data trading based } \\
\text { on Bitcoin transactions }\end{array}$ & Delgado et al. & 2017 & $\begin{array}{l}\text { Future Generation Com- } \\
\text { puter Systems }\end{array}$ & $\begin{array}{l}\text { Theoretical } \\
\text { ture }\end{array}$ & Struc- & $\begin{array}{l}\text { Cryptocurrency } \\
\text { Structure }\end{array}$ \\
\hline 30 & $\begin{array}{l}\text { Detecting artificial behaviours in the } \\
\text { Bitcoin users graph }\end{array}$ & $\begin{array}{l}\text { Di Francesco } \\
\text { Maesa et al. }\end{array}$ & 2017 & $\begin{array}{l}\text { Online Social Networks } \\
\text { and Media }\end{array}$ & $\begin{array}{l}\text { Theoretical } \\
\text { ture }\end{array}$ & Struc- & $\begin{array}{l}\text { Cryptocurrency } \\
\text { Structure }\end{array}$ \\
\hline 31 & $\begin{array}{l}\text { Runtime verification for business pro- } \\
\text { cesses utilizing the Bitcoin blockchain }\end{array}$ & Prybila et al. & 2018 & $\begin{array}{l}\text { Future Generation Com- } \\
\text { puter Systems }\end{array}$ & $\begin{array}{l}\text { Theoretical } \\
\text { ture }\end{array}$ & Struc- & $\begin{array}{l}\text { Cryptocurrency } \\
\text { Structure }\end{array}$ \\
\hline 32 & $\begin{array}{l}\text { Bitcoin-based fair payments for out- } \\
\text { sourcing computations of fog devices }\end{array}$ & Huanga et al. & 2018 & $\begin{array}{l}\text { Future Generation Com- } \\
\text { puter Systems }\end{array}$ & $\begin{array}{l}\text { Theoretical } \\
\text { ture }\end{array}$ & Struc- & $\begin{array}{l}\text { Cryptocurrency } \\
\text { Structure }\end{array}$ \\
\hline
\end{tabular}


Table 2: Key characteristics of included quantitative research

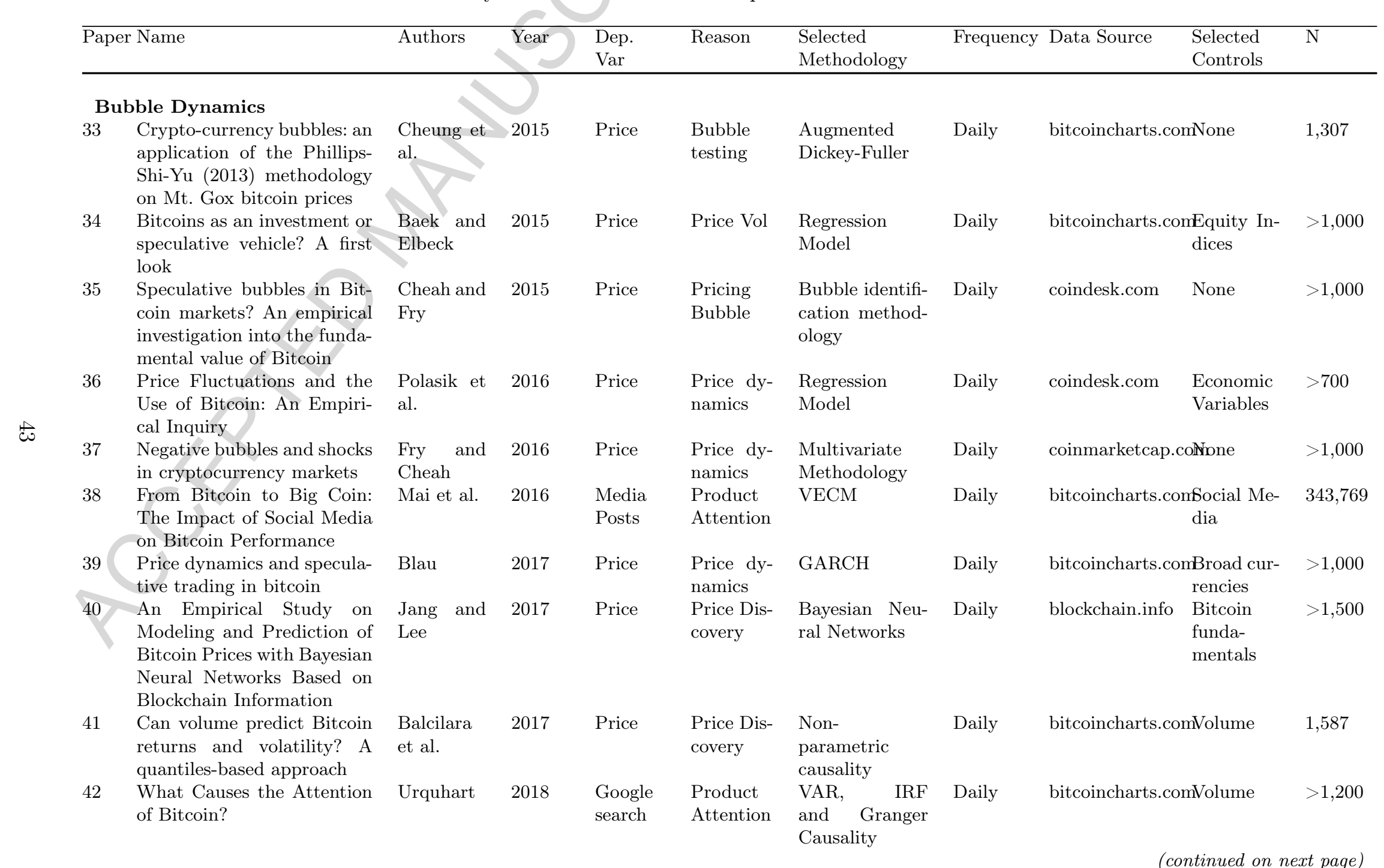


Table 2: Key characteristics of included quantitative research

\begin{tabular}{|c|c|c|c|c|c|c|c|c|c|c|c|}
\hline \multicolumn{2}{|c|}{ Paper Name } & Authors & Year & $\begin{array}{l}\text { Dep. } \\
\text { Var }\end{array}$ & Reason & $\begin{array}{l}\text { Selected } \\
\text { Methodology }\end{array}$ & Frequency & \multicolumn{2}{|c|}{ Data Source } & \multirow{2}{*}{$\begin{array}{l}\begin{array}{l}\text { Selected } \\
\text { Controls }\end{array} \\
\text { None }\end{array}$} & $\mathrm{N}$ \\
\hline 43 & $\begin{array}{l}\text { A new look at Cryptocur- } \\
\text { rencies }\end{array}$ & $\begin{array}{l}\text { Phillip et } \\
\text { al. }\end{array}$ & 2018 & Price & $\begin{array}{l}\text { Market } \\
\text { Vol }\end{array}$ & $\begin{array}{l}\text { Stochastic } \text { Vol } \\
\text { Model }\end{array}$ & $\begin{array}{l}\text { Cross- } \\
\text { section }\end{array}$ & $\begin{array}{l}\text { Brave } \\
\text { Coin }\end{array}$ & New & & 1,225 \\
\hline 44 & $\begin{array}{l}\text { An application of extreme } \\
\text { value theory to cryptocur- } \\
\text { rencies }\end{array}$ & $\begin{array}{l}\text { Gkillas } \\
\text { and Katsi- } \\
\text { ampa }\end{array}$ & 2018 & Price & $\begin{array}{l}\text { Market } \\
\text { Risk }\end{array}$ & $\begin{array}{l}\text { VaR, Expected } \\
\text { Shortfall }\end{array}$ & Daily & coindes &.$c o m$ & $\begin{array}{l}\text { Other } \\
\text { cryptocur- } \\
\text { rencies }\end{array}$ & 2,655 \\
\hline 45 & $\begin{array}{l}\text { Datestamping the Bitcoin } \\
\text { and Ethereum bubbles }\end{array}$ & $\begin{array}{l}\text { Corbet et } \\
\text { al. }\end{array}$ & 2018 & Price & $\begin{array}{l}\text { Price dy- } \\
\text { namics }\end{array}$ & $\begin{array}{l}\text { Regression } \\
\text { Model }\end{array}$ & Daily & coindes &.$c 0 m$ & None & 3,227 \\
\hline 46 & $\begin{array}{l}\text { The best of two worlds: } \\
\text { Forecasting high frequency } \\
\text { volatility for cryptocurren- } \\
\text { cies and traditional curren- } \\
\text { cies with Support Vector Re- } \\
\text { gression }\end{array}$ & Peng et al. & 2018 & Price & $\begin{array}{l}\text { Price } \\
\text { Volatility }\end{array}$ & GARCH & Daily & $\begin{array}{l}\text { Altcoin } \\
\text { Charts }\end{array}$ & & $\begin{array}{l}\text { Currency } \\
\text { (Euro, } \\
\text { Yen, } \\
\text { Pound) }\end{array}$ & $>400$ \\
\hline 47 & $\begin{array}{l}\text { The economics of Bitcoin } \\
\text { and similar private digital } \\
\text { currencies }\end{array}$ & Dwyer & 2015 & Price & $\begin{array}{l}\text { Price dy- } \\
\text { namics }\end{array}$ & $\begin{array}{l}\text { Literature Re- } \\
\text { view }\end{array}$ & Daily & None & & None & $>700$ \\
\hline & $\begin{array}{l}\text { The Evolution of the Bit- } \\
\text { coin Economy: Extracting } \\
\text { and Analyzing the Network } \\
\text { of Payment Relationships }\end{array}$ & $\begin{array}{l}\text { Tasca et } \\
\text { al. }\end{array}$ & 2016 & $\begin{array}{l}\text { Block } \\
\text { height }\end{array}$ & $\begin{array}{l}\text { Use of } \\
\text { Bitcoin }\end{array}$ & $\begin{array}{l}\text { Network Anal- } \\
\text { ysis }\end{array}$ & Tick/HF & Bitcoin & Core & None & 355,551 \\
\hline & $\begin{array}{l}\text { Does Governance Have a } \\
\text { Role in Pricing? Cross- } \\
\text { Country Evidence From } \\
\text { Bitcoin Markets }\end{array}$ & Viglione & 2017 & Price & $\begin{array}{l}\text { Price dy- } \\
\text { namics }\end{array}$ & $\begin{array}{l}\text { Regression } \\
\text { Model }\end{array}$ & Daily & quandl. & om & $\begin{array}{l}\text { Equity In- } \\
\text { dices }\end{array}$ & 342 \\
\hline 50 & Bitcoin and the bailout & $\begin{array}{l}\text { Luther } \\
\text { and Salter }\end{array}$ & 2017 & $\begin{array}{l}\text { App } \\
\text { Down- } \\
\text { loads }\end{array}$ & $\begin{array}{l}\text { Transferring } \\
\text { deposits } \\
\text { (bank } \\
\text { run) }\end{array}$ & Pareto Ranking & Daily & $\begin{array}{l}\text { Apple } \\
\text { Store }\end{array}$ & App & None & 728 \\
\hline
\end{tabular}


Table 2: Key characteristics of included quantitative research

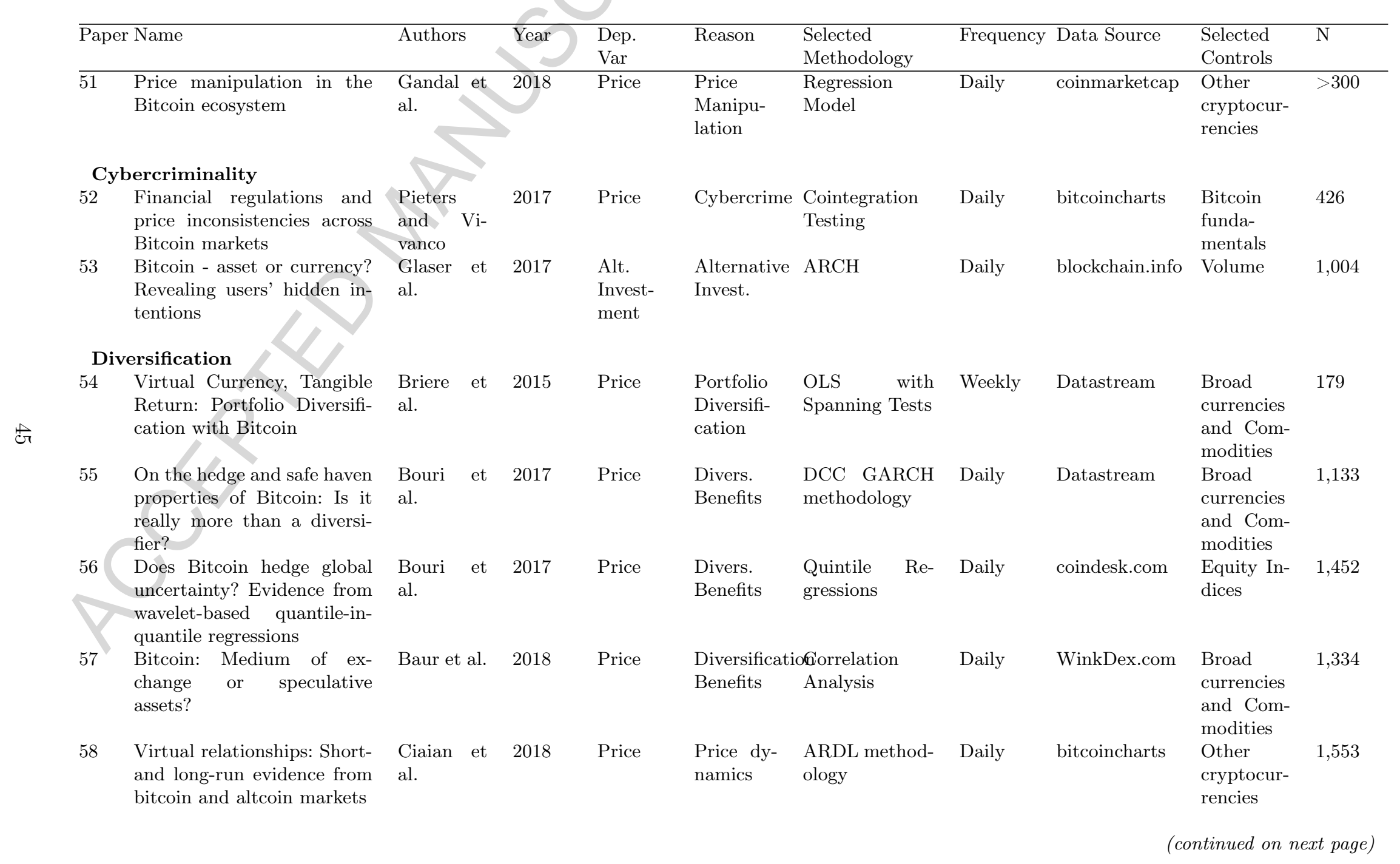


Table 2: Key characteristics of included quantitative research

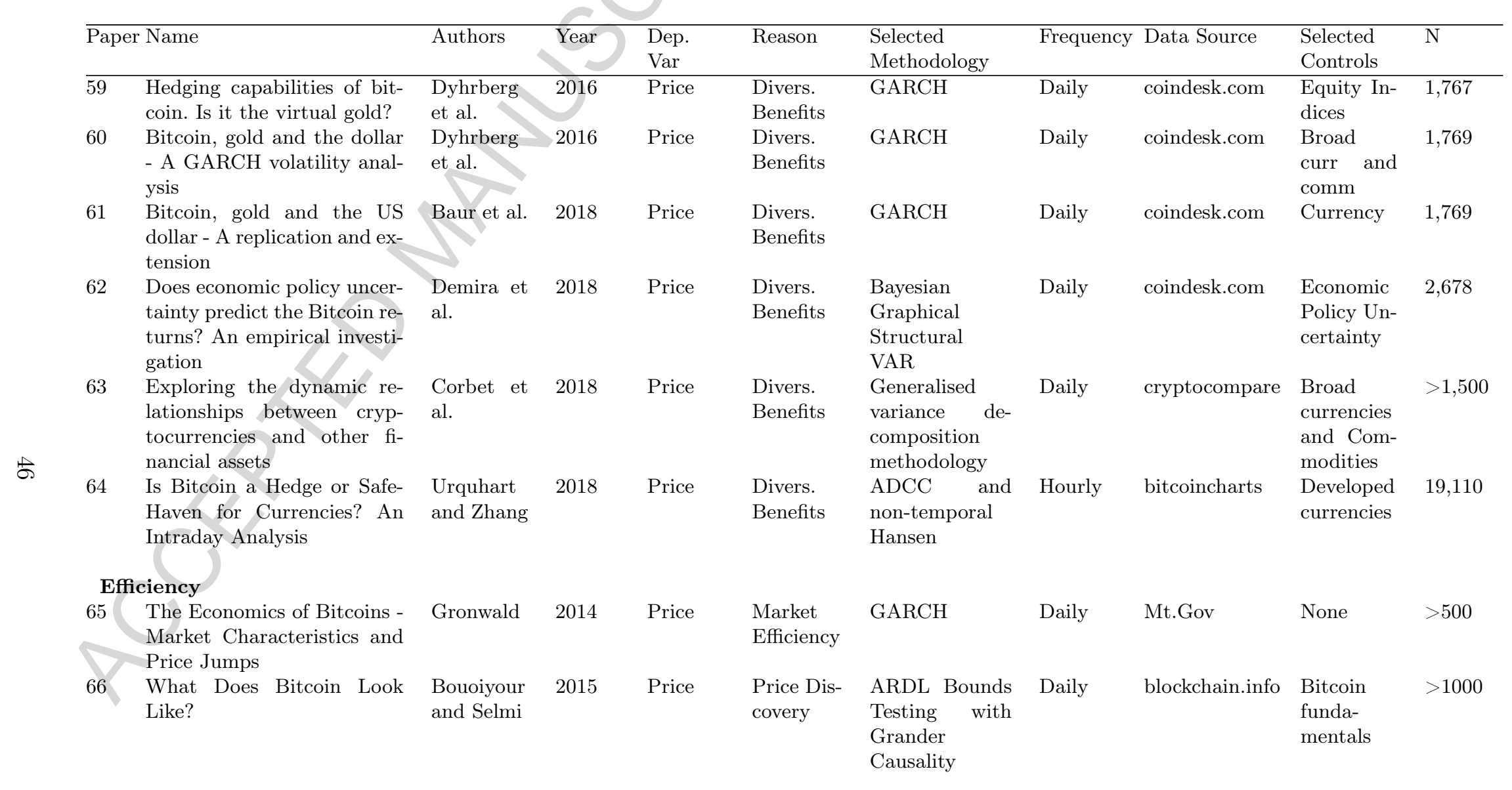


Table 2: Key characteristics of included quantitative research

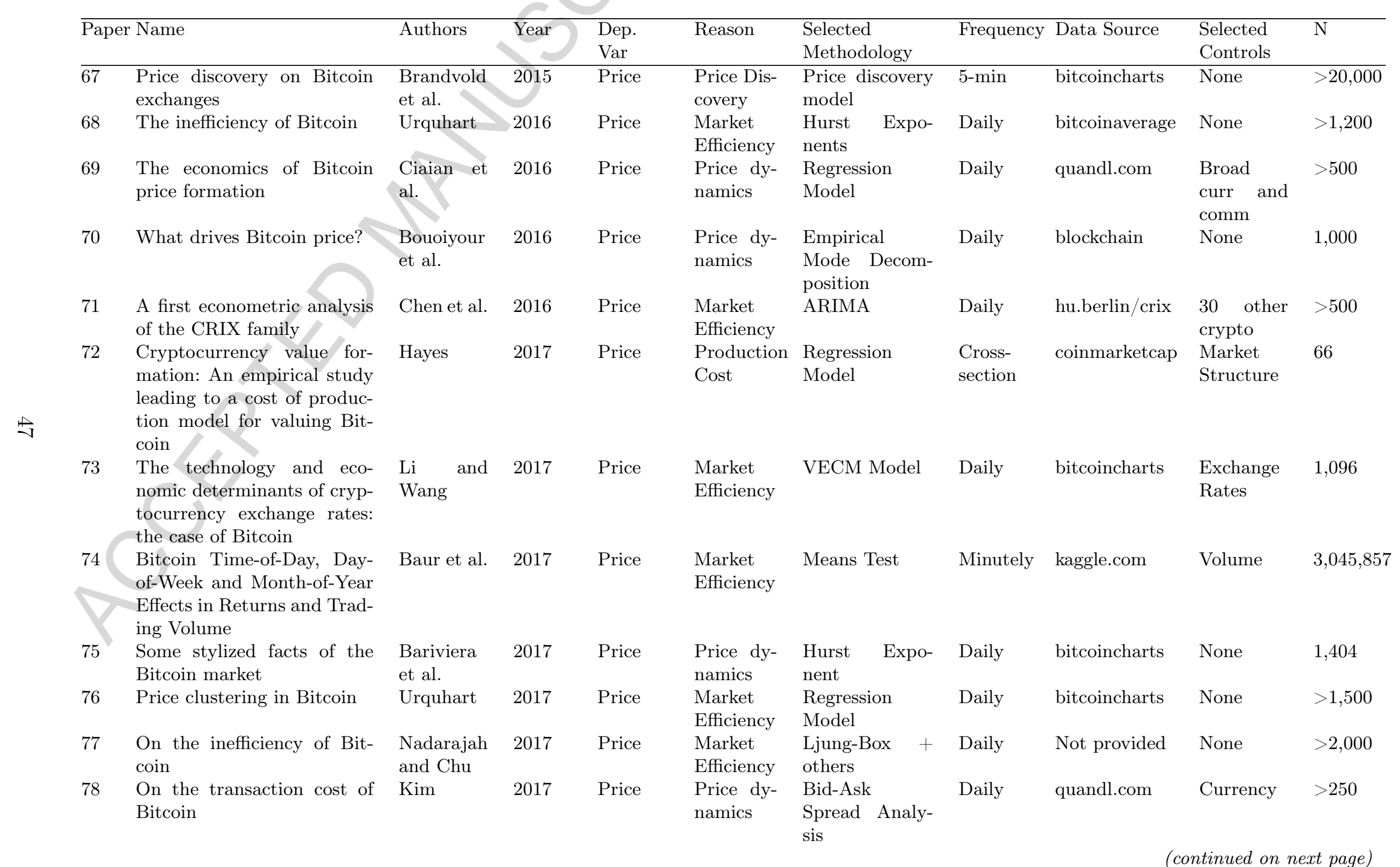


Table 2: Key characteristics of included quantitative research

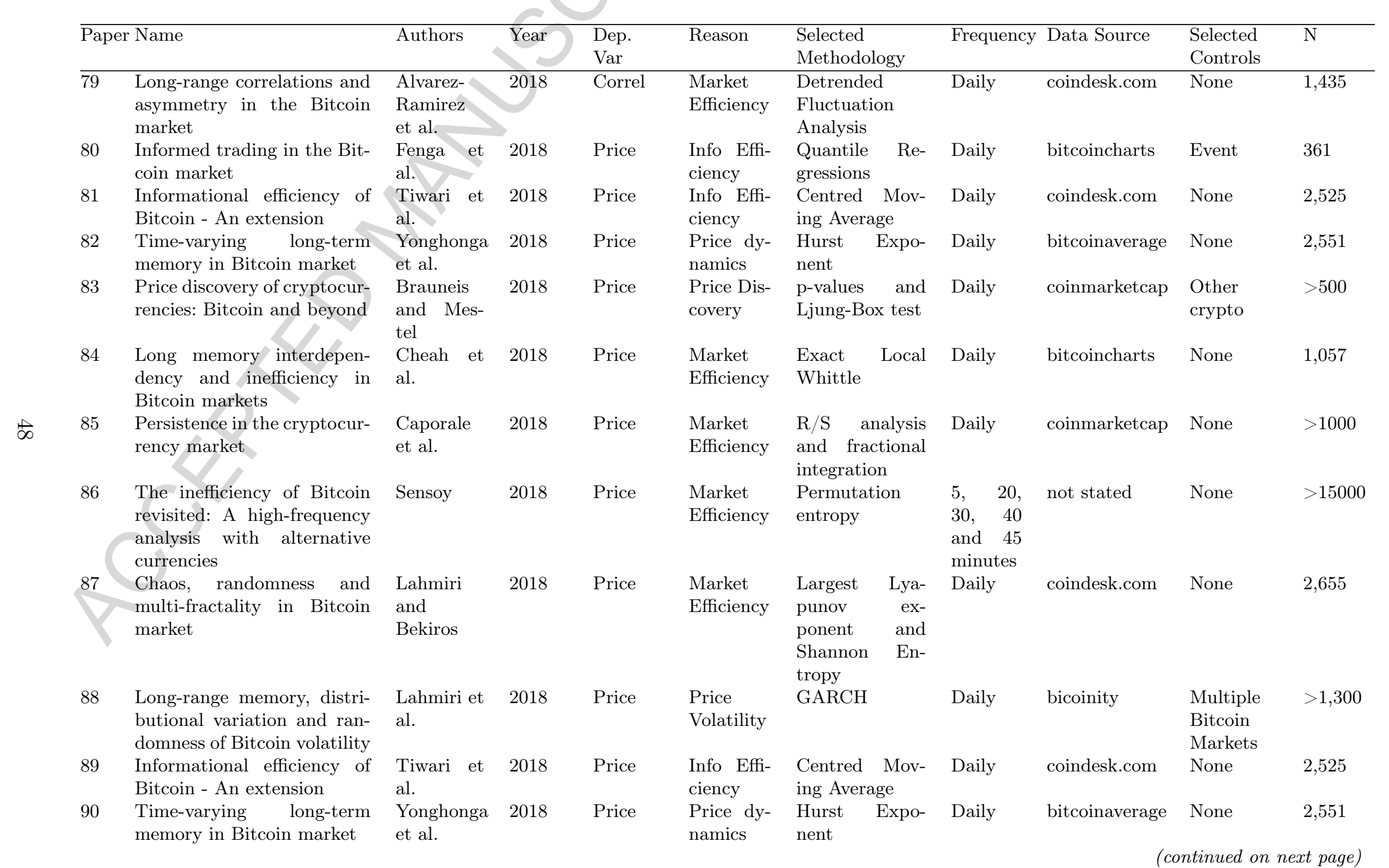


Table 2: Key characteristics of included quantitative research

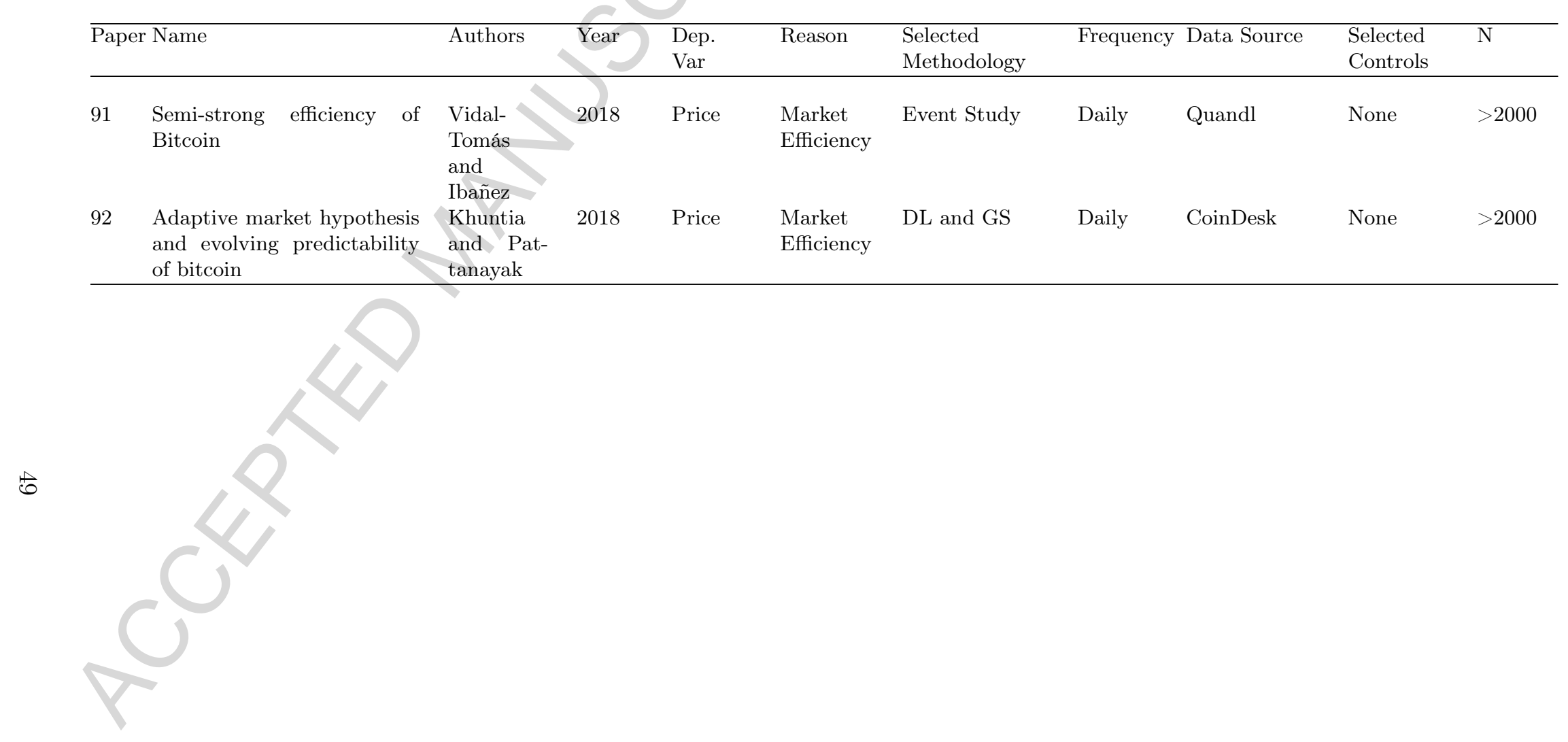


Table 3: Core research topics of the papers presented in Table 2

\begin{tabular}{ll}
\hline Core Research Topic & Count \\
\hline Bitcoin taxation & 2 \\
Bubble testing & 1 \\
Cryptocurrency Structure & 18 \\
Cybercrime & 6 \\
Diversification Benefits & 11 \\
Future of Digital Payments & 1 \\
Informational Efficiency & 2 \\
Legal & 1 \\
Market Distribution & 1 \\
Market Efficiency & 26 \\
Market Risk & 1 \\
Market Volatility & 1 \\
Overview of Legal Structure & 1 \\
Portfolio Diversification & 1 \\
Potential other uses for blockchain & 1 \\
Price Discovery & 5 \\
Price dynamics & 12 \\
Price Volatility & 4 \\
Product Attention/Social Media & 2 \\
Regulation & 7 \\
\hline
\end{tabular}

Table 4: Sources of data utilised in quantitative methods presented in Table 2

\begin{tabular}{ll}
\hline Data Source & Count \\
\hline Altcoin Charts & 1 \\
Apple App Store & 1 \\
Bicoinity & 1 \\
Bitcoin Core & 1 \\
Bitcoinaverage.com & 2 \\
Bitcoincharts.com & 15 \\
Blockchain.info & 4 \\
Brave New Coin Digital Indices & 1 \\
Coindesk.com & 13 \\
Coinmarketcap.com & 5 \\
Cryptocompare.com & 1 \\
Datastream & 2 \\
hu.berlin/crix & 1 \\
kaggle.com & 1 \\
Mt.Gov & 1 \\
Quandl.com & 4 \\
WinkDex.com & 1 \\
\hline
\end{tabular}


Table 5: Gaps in the literature

\begin{tabular}{ll}
\hline Number & Gap \\
\hline 1 & Expand datasets and number of cryptocurrencies studied \\
2 & Study the legal, economic and regulatory issues of cryptocurrencies \\
3 & Asymmetrical information issues \\
4 & Theoretical Development \\
5 & Alternative potential benefits and uses of blockchain \\
6 & Evaluate the benefits of cryptocurrencies separately, and not as one large asset class \\
7 & Evaluate cryptocurrencies based on their use, rather than just their financial performance \\
8 & Address the environmental challenges of cryptocurrencies \\
9 & Evaluate the benefits of cryptocurrencies as an asset class part of a diversified portfolio \\
10 & Ongoing study of cryptocurrencies since their behaviour is continually changing \\
\hline
\end{tabular}


Khuntia and Pattanayak (2018)

Corbet et al. (2018b)

Tasca et al. (2016)

Ciaian et al. (2016)

Demira et al. (2018)

Lahmiri and Bekiros (2018)

Gkillas and Katsiampa(2018)

Tiwari et al. (2018)

Bauret al. (2018b)

Bauretal. (2018a)

Dyhrberg (2016b)

Dyhrberg (2016a)

Viglione (2017)

Cheau and Fry (2015)

Blau (2017)

Cheung et al. (2015)

Baek and El beck (2015)

Brière et al. (2015)

Dwyer (2015)

Urquhart (2018)

Nadaraj ah and Chu (2017)

Urquhart (2016)

Yonghongaet al. (2018)

Bauretal. (2017)

Bouoiyour et al. (2010)

Bouoiyour and Selmi 12015)

Vidal-Thomas and lbanez (2018)

Barivieraet al. (2017)

Fry and Cheah (2016)

Li and Wang (2017)

Gronwald (2014)

Bouriet al. (2017b)

Polasik etal. (2016)

Bouriet al. (2017a)

Fengaet al. (2018)

Cheah et al (2018)

Balcilara et al. (2017)

Bai, Wang and Chi ang (2016)

Urquhart (2017)

Gandal et al. (2018)

Sensoy (2018)

Corbetet al. (2018a)

Ciaianet al. (2018)

Brandvoldet al. (2015)

Caporale et al (2018)

Alvarez-Ramirez et al. (2018)

Florian et al. (2017)

Lahmiri et al. (2018)

Kim(2017)

Pieters and Vivanco (2017)

Chenet al. (2016)

Urquhart and Zhang (2018)

Braunei s and Mestel (2018)

Peng et al . (2018)

Phillp, Chan and Peiris (2018)

Jang and Lee (2017)
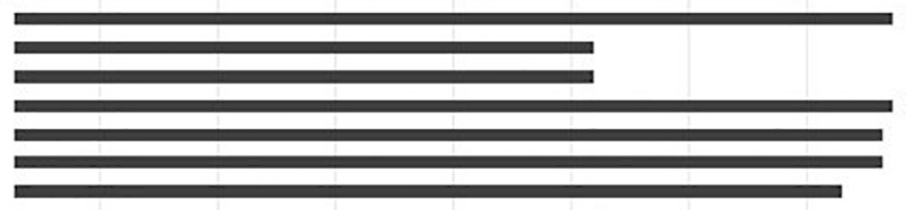

-

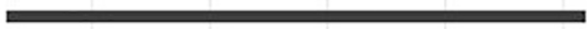



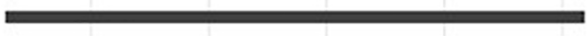

-
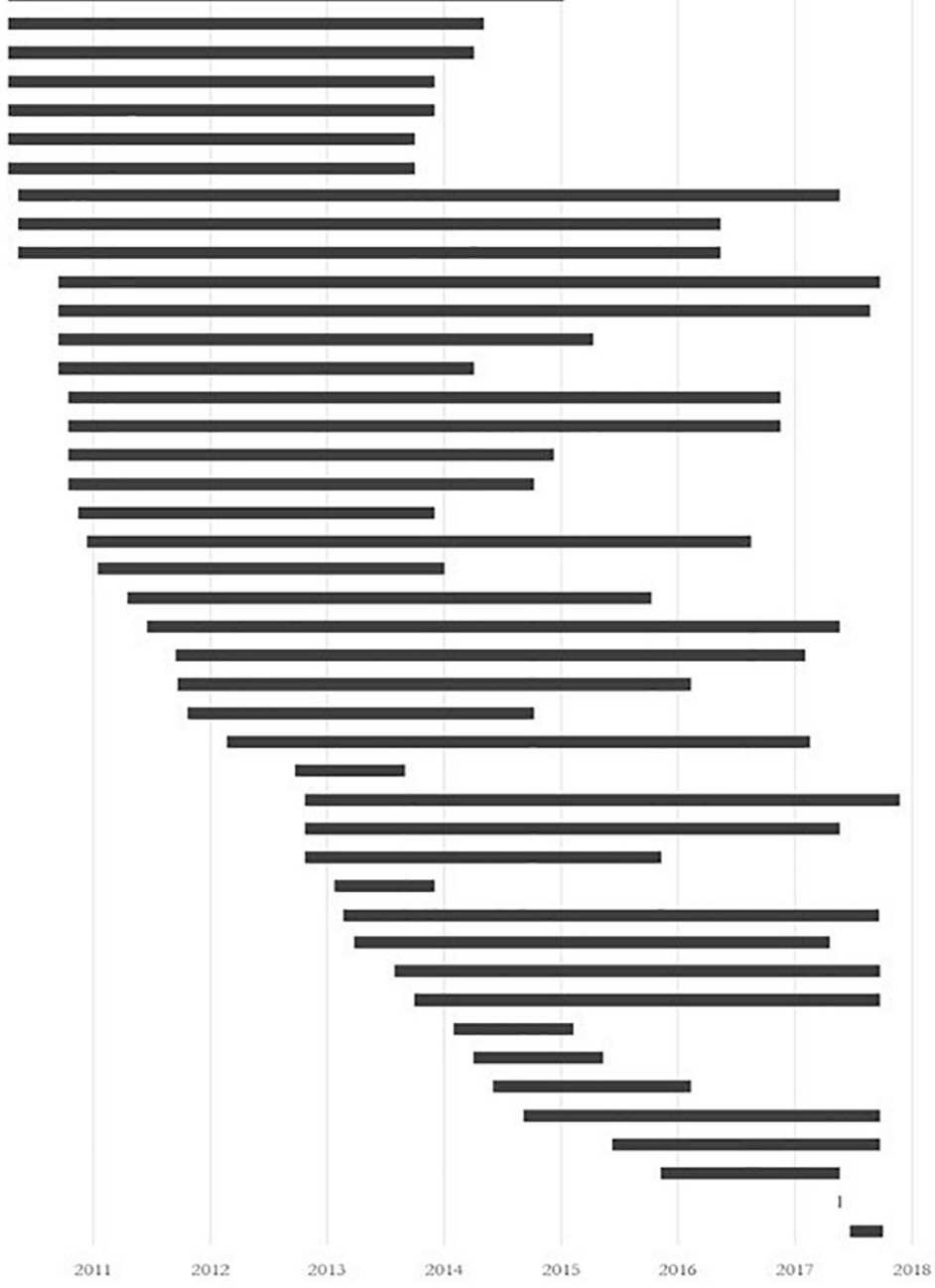

Years of Data Coverage

Figure 1 


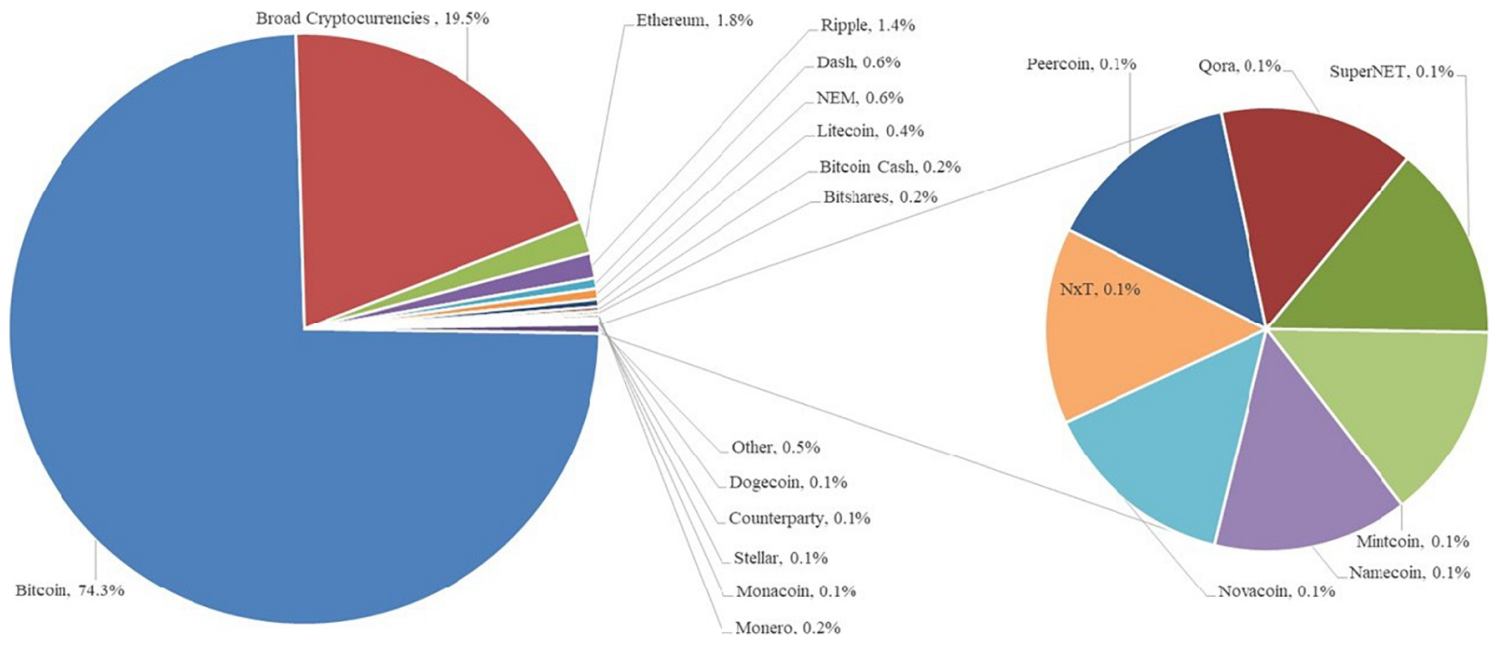

Figure 2 

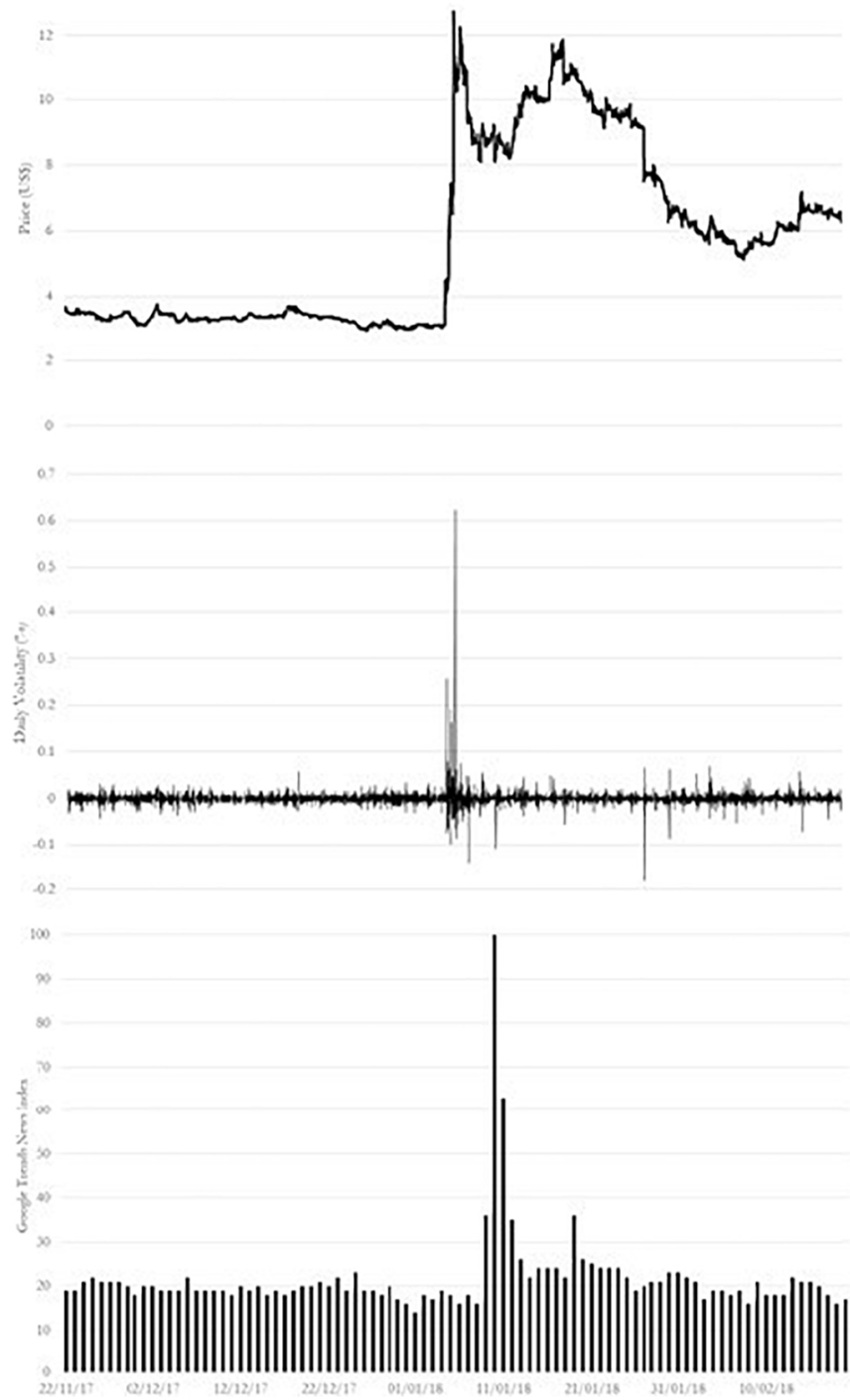

Figure 3 


\section{Potential for inherent bubbles}

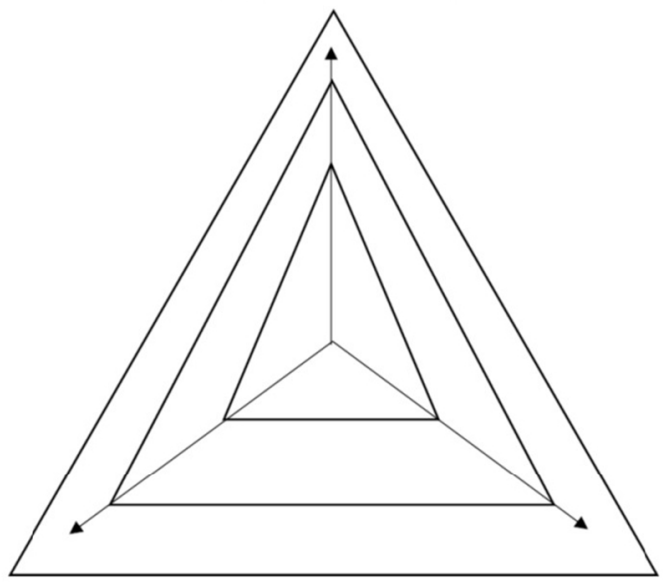

Regulatory alignment

Cybercriminality

Figure 4 
80

60
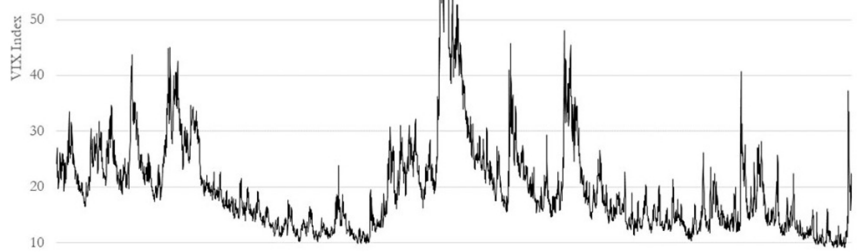

0

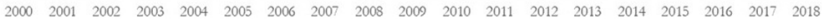

Figure 5 

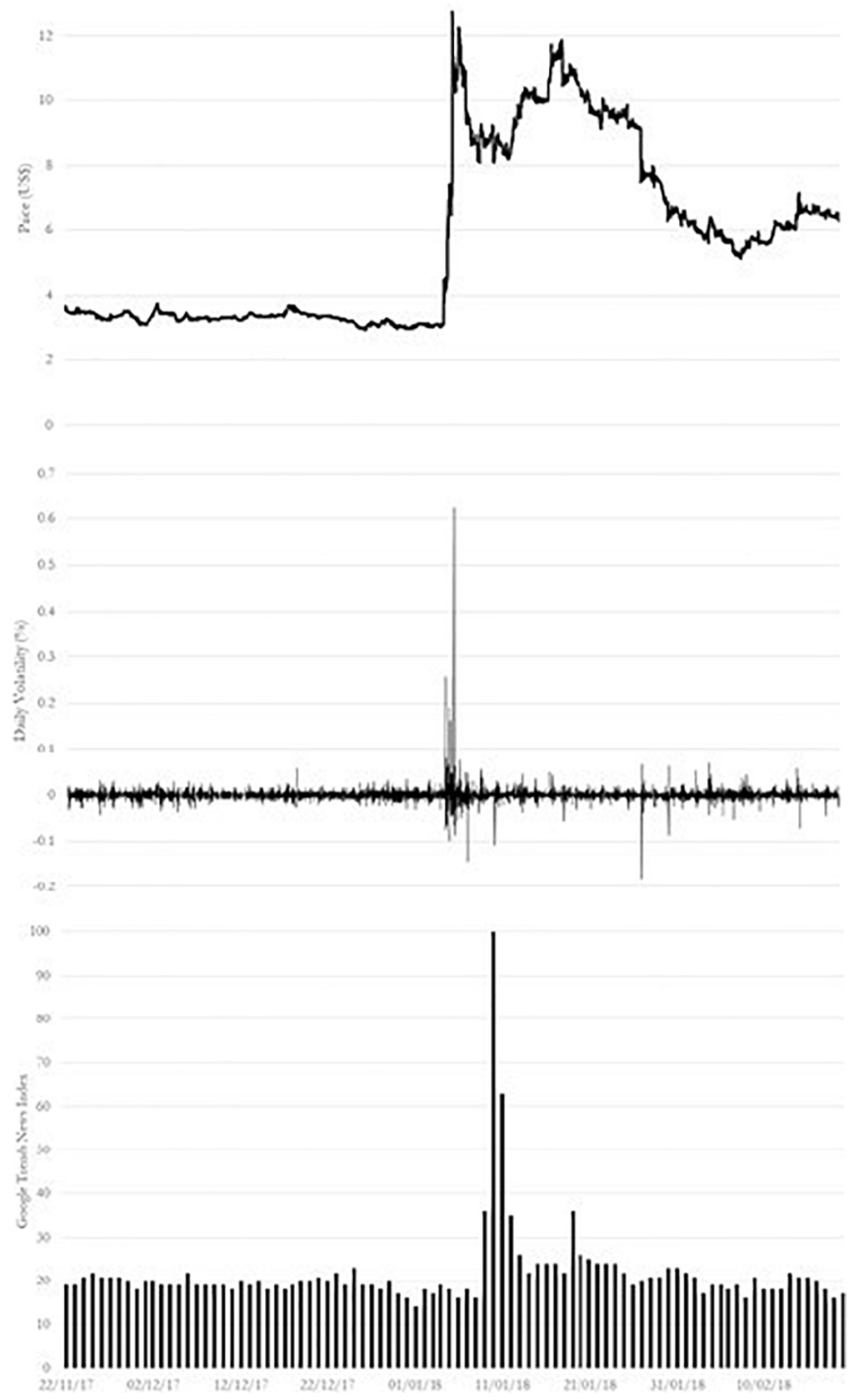

Figure 6 